\title{
UMA PROPOSTA DE RELAÇÃO DE REQUISITOS FUNCIONAIS PARA UM SOFTWARE DE APOIO AO PROCESSO DE INTELIGÊNCIA
}

Fábio Luiz de Carvalho Rios

fabio.rios@plugar.com.br

Universidade Federal do Rio Grande do Sul - Porto Alegre, RS / Brasil

\section{Raquel Janissek-Muniz}

rjmuniz@ea.ufrgs.br

Universidade Federal do Rio Grande do Sul - Porto Alegre, RS / Brasil

http://dx.doi.org/10.1590/1413-2311056201238165

Recebido em 07/10/2013

Aprovado em 30/04/2014

Disponibilizado em 01/08/2014

Avaliado pelo sistema double blind review

Revista Eletrônica de Administração

Editor: Luís Felipe Nascimento

ISSN 1413-2311 (versão on-line)

Editada pela Escola de Administração da Universidade Federal do Rio Grande do Sul.

Periodicidade: Quadrimestral

Sistema requerido: Adobe Acrobat Reader.

\section{RESUMO}

Com o aumento da competição, estabeleceu-se a necessidade pelo acompanhamento do que os concorrentes estão fazendo e o que os clientes estão querendo. No Brasil, desde o início dos anos 2000, surgiram com maior ênfase metodologias que vão ao encontro deste olhar para o ambiente externo, denominadas metodologias de inteligência. São inúmeras, e se propõem a apoiar as organizações no processo de obtenção e uso de informações. Com a Internet, cada vez mais informações estão disponíveis para proporcionar o acompanhamento do que está acontecendo em cada um dos ambientes de competição onde as organizações estão inseridas. Desta forma, levando-se em consideração as metodologias de inteligência disponíveis e as premissas sobre grandes volumes de informações para acompanhamento dos ambientes de competição, faz sentido imaginar que um software possa contribuir neste cenário. Entretanto, quais requisitos funcionais um software de apoio ao processo de inteligência deveria ter? Esta é a principal questão que este trabalho busca responder. Através de extensa pesquisa bibliográfica na área de administração e entrevistas em profundidade com especialistas e profissionais em inteligência, foi possível identificar funcionalidades para, ao final deste estudo, propor uma relação de requisitos funcionais de software capaz de contribuir para este importante processo adotado nas principais organizações brasileiras.

Palavras-Chave: Inteligência; Software; Requisitos Funcionais; Metodologia de Inteligência.

\section{A PROPOSAL FOR A LIST OF SOFTWARE FEATURES}

TO SUPPORT A INTELLIGENCE PROCESS

\author{
ABSTRACT \\ REAd | Porto Alegre - Edição 78 - N 2 - maio/agosto 2014 - p. 425-460
}


Uma proposta de relação de requisitos funcionais para um software de apoio ao processo de

inteligência

The growth in competition, has called for both the need to follow the activities of competitors, and the needs of clients. Brazil, since the beginning of the 2000s, has witnessed a greater emphasis on methodologies focused on observing an organization's external environment, also known as intelligence methodologies. They are many, and all these target on assisting organizations, in one way or another, in acquiring and using information. With the growth of the internet, more and more information is being generated which allows the monitoring of the competitive environment in which organizations operate. Thus, taking into account the methodologies and assumptions intelligence available to large volumes of information for monitoring of competition environments, it makes sense to imagine that a software can help in this scenario. However, this brings up the issue of knowing which features should such an application have? This is the main subject of this study. Via extensive bibliographical research and interviews with both specialists and professionals in the field of intelligence, it was possible to formulate a proposal for a structured checklist of functionalities that a software application should have to be of true assistance in this vital process which is currently being adopted in many Brazilian organizations.

Keywords: intelligence; software; software features; intelligence methodologies.

\section{PROPUESTA DE REQUISITOS FUNCIONALES POR UN PROGRAMA DE APOYO DE INTELIGENCIA}

Con el aumento de la competencia, se estableció la necesidad de monitorear lo que los competidores están haciendo y lo que los clientes están deseando. En Brasil, desde principios de la década de 2000, surgió con mayor énfasis las metodologías que respondan a este aspecto en el entorno externo, llamado metodologías de inteligencia. Son numerosos, y están destinados a ayudar a las organizaciones en la obtención y el uso de proceso de información. Con Internet, más y más información están disponibles para proporcionar la supervisión de lo que está sucediendo en cada entorno de competencia donde se encuentran las organizaciones. Por lo tanto, teniendo en cuenta las metodologías y supuestos inteligencia disponible a grandes volúmenes de información para el monitoreo de los ambientes de competencia, tiene sentido imaginar que un software puede ayudarle en este escenario. Sin embargo, ¿qué requisitos funcionales de software para apoyar el proceso de inteligencia deben tener? Esta es la pregunta principal que este documento trata de responder. A través de una extensa investigación la literatura en el ámbito de la administración y de entrevistas en profundidad con expertos y profesionales de la inteligencia, fue posible identificar características para, al final de este estudio, sugierer una lista de los requisitos funcionales de software que es capaz de contribuir a este importante proceso adoptado en las principales organizaciones do Brasil.

Palabras clave: Inteligencia; Software; Requisitos funcionales; Metodología de Inteligencia.

\section{INTRODUÇÃO}

A importância da informação nas organizações tem sido tema recorrente de pesquisas, palestras, conferências e consultorias. A informação é vista como principal recurso das organizações, a verdadeira diferenciação (MARCHAND et al, 2004), que deve, portanto, ser gerida adequadamente. Dentro desta preocupação, um tipo específico de monitoramento, que analisa o ambiente externo, tem chamado atenção de empresários e acadêmicos no Brasil. 
Trata-se da inteligência aplicada ao ambiente de negócios. A inteligência faz parte da gestão da informação de uma organização, uma vez que se preocupa com o ambiente externo, um dos ambientes da gestão da informação apontados por Davenport (1998).

As práticas de inteligência estão cada vez mais difundidas para tornar as organizações competitivas e melhor preparadas para avançar em seus ambientes de competição, o que torna fundamental fomentar estas metodologias nas organizações brasileiras. Para a realização de inteligência, faz-se fundamental o uso de informações, oriundas de jornais/revistas, Internet, bancos de dados, pesquisas de mercado, contatos com fornecedores, etc. (MILLER, 2002). Entretanto, com a Internet, eleva-se substancialmente o volume de dados. O tráfego de dados a partir de dispositivos móveis com acesso à internet (laptops, note e netbooks, smartphones, tablets, etc.) está crescendo tão rapidamente que, se a tendência atual continuar a mesma, em 2014, o volume mensal vai superar o total registrado em 2008 (INFOMONEY, 2010).

Por outro lado, mesmo com um número maior de informações, não há crescimento do número de profissionais responsáveis pela operacionalização da inteligência nas organizações que possuem processos estruturados. Segundo Marcial (2007), a maioria das empresas que têm uma atividade de inteligência instalada possui apenas um funcionário dedicado. Sendo as informações insumos essenciais para alimentar os processos de inteligência, como fazer para que poucos profissionais possam tratar milhares de informações?

Uma forma de tratar tais quantidades de informações disponíveis para o processo de inteligência é usando a tecnologia da informação. Neste sentido, Tarapanoff (2001) afirma que para ter inteligência é preciso contar com uma infraestrutura adequada, utilizando sistemas e telecomunicações. Mesmo sendo um processo essencialmente cognitivo, que depende diretamente da percepção e do raciocínio humano, algumas de suas etapas podem ser alavancadas com a utilização de tecnologia. Neste sentido, um software de apoio ao processo de inteligência poderia apoiar organizações a estruturar suas demandas e identificar ameaças e oportunidades para os seus negócios em meio a tantas informações. Com as etapas do processo de inteligência automatizadas, os usuários teriam velocidade e produtividade no desenvolvimento de relatórios, estudos e planos de recomendação de inteligência.

Entretanto, para que um software possa apoiar no processo de inteligência, o mesmo deve ser desenvolvido sob a ótica clara de quais atividades deverá automatizar. Certamente, em um processo de inteligência, não serão todas, devido à questão fundamental do envolvimento humano no processo, suas percepções e interpretações. Ainda, neste sentido, de acordo com Krafta (2007), muitos dos fracassos de empresas em relação aos projetos de TI

REAd | Porto Alegre - Edição 78 - N 2 - maio/agosto 2014 - p. 425-460 
Uma proposta de relação de requisitos funcionais para um software de apoio ao processo de inteligência

podem ser explicados pela lacuna entre a expectativa dos usuários em relação a um sistema de informação e quanto esta expectativa é de fato atendida. Diversos softwares de inteligência existem no mercado (Quadro 1), entretanto nenhum concentra funcionalidades capazes de atender a todas as etapas do processo de inteligência. Segundo Turine e Masiero (1996), uma funcionalidade define os requisitos funcionais que o software ou componentes do software devem executar. Diz respeito à finalidade a que se propõe o produto de software e compõe características de qualidade para qualquer tipo de software. É ainda o conjunto de atributos (adequação, acurácia, interoperabilidade, conformidade, segurança) que evidenciam a existência de um conjunto de funções que satisfazem as necessidades explícitas e implícitas.

Quadro 1 - Relação de softwares disponíveis no mercado

\begin{tabular}{|c|c|c|}
\hline Software & Empresa & Descrição \\
\hline BrainEKP & $\begin{array}{l}\text { TheBrain } \\
\text { Technologies }\end{array}$ & $\begin{array}{l}\text { Software de classificação automática de informações a partir de árvores } \\
\text { informacionais. A ferramenta identifica relações e correlações entre termos, } \\
\text { permitindo que o próprio usuário realize suas classificações. }\end{array}$ \\
\hline e-Monitora & Plugar & $\begin{array}{l}\text { Software de apoio ao processo de inteligência, capaz de contribuir no } \\
\text { armazenamento e no envio de informações. Possui recursos para permitir a } \\
\text { categorização manual de conteúdos }\end{array}$ \\
\hline EyeBot & Plugar & $\begin{array}{l}\text { Software de busca corporativa em grandes volumes de documentos. Possui } \\
\text { funcionalidades para identificação automática de termos, relevância de pesquisa, } \\
\text { entre outros recursos que oferecem velocidade na busca de informações. }\end{array}$ \\
\hline $\begin{array}{l}\text { Fast } \\
\text { Enterprise } \\
\text { Search }\end{array}$ & Microsoft & $\begin{array}{l}\text { Software de busca corporativa em grandes volumes de documentos. Possui } \\
\text { funcionalidades para identificação automática de termos, relevância de pesquisa, } \\
\text { entre outros recursos que oferecem velocidade na busca de informações. }\end{array}$ \\
\hline $\begin{array}{l}\text { IDOL } \\
\text { Platform }\end{array}$ & Autonomy & $\begin{array}{l}\text { Software de busca corporativa em grandes volumes de documentos. Possui } \\
\text { funcionalidades para identificação automática de termos, relevância de pesquisa, } \\
\text { entre outros recursos que oferecem velocidade na busca de informações. }\end{array}$ \\
\hline $\begin{array}{l}\text { Knowledge } \\
\text { Works }\end{array}$ & Cipher & $\begin{array}{l}\text { Software de apoio a construção e a operacionalização de KITs e KIQs, variáveis } \\
\text { relacionadas a metodologia americana de IC. Possui funcionalidades para a } \\
\text { identificação automática de termos, sumarização e busca na Internet. }\end{array}$ \\
\hline $\begin{array}{l}\text { Plataforma } \\
\text { Cortex } \\
\text { Competitiva }\end{array}$ & $\begin{array}{l}\text { Cortex } \\
\text { Intelligence }\end{array}$ & $\begin{array}{l}\text { Software de busca corporativa em grandes volumes de documentos. Possui } \\
\text { funcionalidades para identificação automática de termos, relevância de pesquisa, } \\
\text { entre outros recursos que oferecem velocidade na busca de informações. }\end{array}$ \\
\hline SAPIC & Plugar & $\begin{array}{l}\text { Software de apoio ao processo de inteligência. Possui funcionalidades para } \\
\text { apoiar na execução diária das etapas do processo de inteligência e alguns } \\
\text { recursos para a identificação automática de termos e correlações. }\end{array}$ \\
\hline Sphinx Léxica & Sphinx & $\begin{array}{l}\text { Software para pesquisa e análise de dados, capaz de apoiar demandas de } \\
\text { inteligência. Com funções para realização de análise de conteúdo e léxica, } \\
\text { facilitando a percepção de correlações entre grandes volumes de informações. }\end{array}$ \\
\hline STRATEGY! & $\begin{array}{l}\text { Strategy } \\
\text { Software }\end{array}$ & $\begin{array}{l}\text { Software de classificação automática e manual de informações para apoio a } \\
\text { inteligência. Permite o cruzamento de dados e a geração de relatórios. }\end{array}$ \\
\hline Tropes & $\begin{array}{l}\text { Semantic } \\
\text { Knowledge }\end{array}$ & $\begin{array}{l}\text { Software de mineração de texto, sumarização e classificação automática de } \\
\text { informações, capaz de ser aplicado em grandes volumes de documentos. }\end{array}$ \\
\hline Vantage Point & $\begin{array}{l}\text { Vantage } \\
\text { Point }\end{array}$ & $\begin{array}{l}\text { Software de busca corporativa em grandes volumes de documentos. Possui } \\
\text { funcionalidades para identificação automática de termos, relevância de pesquisa, } \\
\text { entre outros recursos que oferecem velocidade na busca de informações. }\end{array}$ \\
\hline $\begin{array}{l}\text { Wincite LAN } \\
\& \text { Screen } \\
\text { DesignModule }\end{array}$ & Wincite & $\begin{array}{l}\text { Software de busca corporativa, captura automática de informações disponíveis } \\
\text { na Internet e geração de páginas para publicação e disseminação de informação. } \\
\text { Possui alguns recursos de visualização de informações. }\end{array}$ \\
\hline
\end{tabular}

Fonte: do autor

REAd | Porto Alegre - Edição 78 - N² 2 - maio/agosto 2014 - p. 425-460 
Para evitar a falta de alinhamento entre o que demanda o processo de inteligência e o que um software de apoio poderia oferecer, é importante o levantamento de requisitos informacionais. Segundo Azevedo Jr e Campos (2008), o levantamento de requisitos permite identificar e modelar as necessidades do negócio a serem atendidas. Para alcançar o objetivo de propor uma relação de requisitos funcionais para um software de apoio ao processo de inteligência, inicialmente identificamos os tipos de inteligência existentes, selecionando os principais para detalhamento de seus ciclos. Isto permitiu consolidar um agrupamento das etapas do processo de inteligência a partir das etapas de cada deles. Em seguida geramos uma relação de requisitos para um software de inteligência com foco em ambiente externo, que foi testada através de entrevistas buscando identificar os principais aspectos a serem observados em um software que apoiaria um processo de inteligência. Ao analisar as opiniões emitidas à luz dos requisitos de software para inteligência, foi igualmente possível perceber elementos adicionais que devem ser observados em estudos complementares.

\section{METODOLOGIA DE PESQUISA}

A metodologia de pesquisa é tratada antes da revisão bibliográfica para proporcionar uma leitura fluída e compreensível da evolução do trabalho como um todo, exatamente da forma como ele foi conduzido. A seção sobre metodologia foi antecipada considerando a necessidade de realização a priori de um trabalho metodológico para atingir os objetivos deste estudo, a saber: identificar tipos de inteligência conforme literatura da área, selecionar os principais e detalhar seus ciclos; e consolidar um esquema de inteligência a partir das etapas pesquisadas.

Esta pesquisa, de abordagem qualitativa (ROESCH, 2005; VIEIRA, 2007) e exploratória (VERGARA, 2006), foi realizada através de Pesquisa Bibliográfica (SILVA e MENEZES, 2001) e Entrevista em Profundidade (MALHOTRA, 2001). Esta escolha se deu por não buscarmos quantificar ou medir os eventos que estão sendo estudados, nem utilizar dados estatísticos como foco do processo de análise de um problema (OLIVEIRA, 2007).

A operacionalização da pesquisa iniciou com Pesquisa Bibliográfica para levantamento de artigos, livros e material da Internet, a partir do qual elegemos os conceitos de inteligência a explorar, além do conceito de requisito funcional de software. Em seguida, detalhamos os tipos de Inteligência, o que permitiu consolidar um esquema único de inteligência (item 3.7.4), gerando o que chamamos de Protocolo Preliminar de Requisitos para 
Uma proposta de relação de requisitos funcionais para um software de apoio ao processo de inteligência

um Software de Inteligência, o qual embasou o roteiro (Quadro 2) para as entrevistas em profundidade.

Quadro 2 - Roteiro revisado para as entrevistas em profundidade

\begin{tabular}{|ll|}
\hline & \multicolumn{1}{c|}{ Como se constrói um processo de inteligência? } \\
\hline - & Sobre a Construção do Processo de Inteligência \\
\hline - & Comunicação e Sensibilização da Empresa \\
\hline Como se operacionaliza um processo de inteligência levando-se em consideração suas \\
etapas (ciclo de inteligência)?
\end{tabular}

Fonte: do autor

As entrevistas foram aplicadas a 4 especialistas +5 profissionais de inteligência. Os especialistas selecionados são nomes de referência ${ }^{1}$ em inteligência, professores, palestrantes e autores de livros sobre o tema. Não foram entrevistados especialistas em software. Quanto aos profissionais ${ }^{2}$, são funcionários que trabalham em áreas de inteligência em empresas brasileiras, advindos de 5 distintas organizações: Dell, Grupo Rede Paranaense de Comunicação (afiliada da Globo no Paraná), Companhia Aliança do Brasil (atual Grupo Mapfre), Universidade de Caxias do Sul e Federação das Indústrias de Minas Gerais (FIEMG). Os profissionais possuem entre 3 e 10 anos de experiência na área de Inteligência.

Já na primeira entrevista percebeu-se a necessidade de complementar a pesquisa em relação à Construção do Processo de Inteligência - pois inicialmente estávamos focando apenas na Operacionalização do Processo. O roteiro foi então adaptado para todas as demais entrevistas. Para análise do material coletado, utilizamos técnica de Análise de Conteúdo (BARDIN, 1996; FREITAS e JANISSEK, 2000) para extrair das entrevistas todos os elementos que poderiam sinalizar requisitos funcionais de software, sejam eles explicitados pelos entrevistados ou identificados na categorização e análise dos dados.

Para um melhor entendimento da sequência realizada, segue o desenho de pesquisa.

\footnotetext{
${ }^{1}$ Prof. Dr. Humbert Lesca, Prof ${ }^{a}$ Dr$^{\text {a }}$ Elisabeth Gomes, Prof ${ }^{a}$ Dr$^{a}$ Raquel Janissek-Muniz e Eduardo Lapa

${ }^{2}$ Rodrigo Mazuchowski (GRPCOM): 8 anos de experiência em inteligência; Piero Torres (Aliança): 3 anos de experiência; Samuel Molina (Dell): 10 anos de experiência; Ronald Lopes (UCS): 10 anos de experiência; e Denise Franco (FIEMG): 10 anos de experiência.
}

REAd | Porto Alegre - Edição 78 - N² 2 - maio/agosto 2014 - p. 425-460 
Fábio Luiz de Carvalho Rios \& Raquel Janissek-Muniz

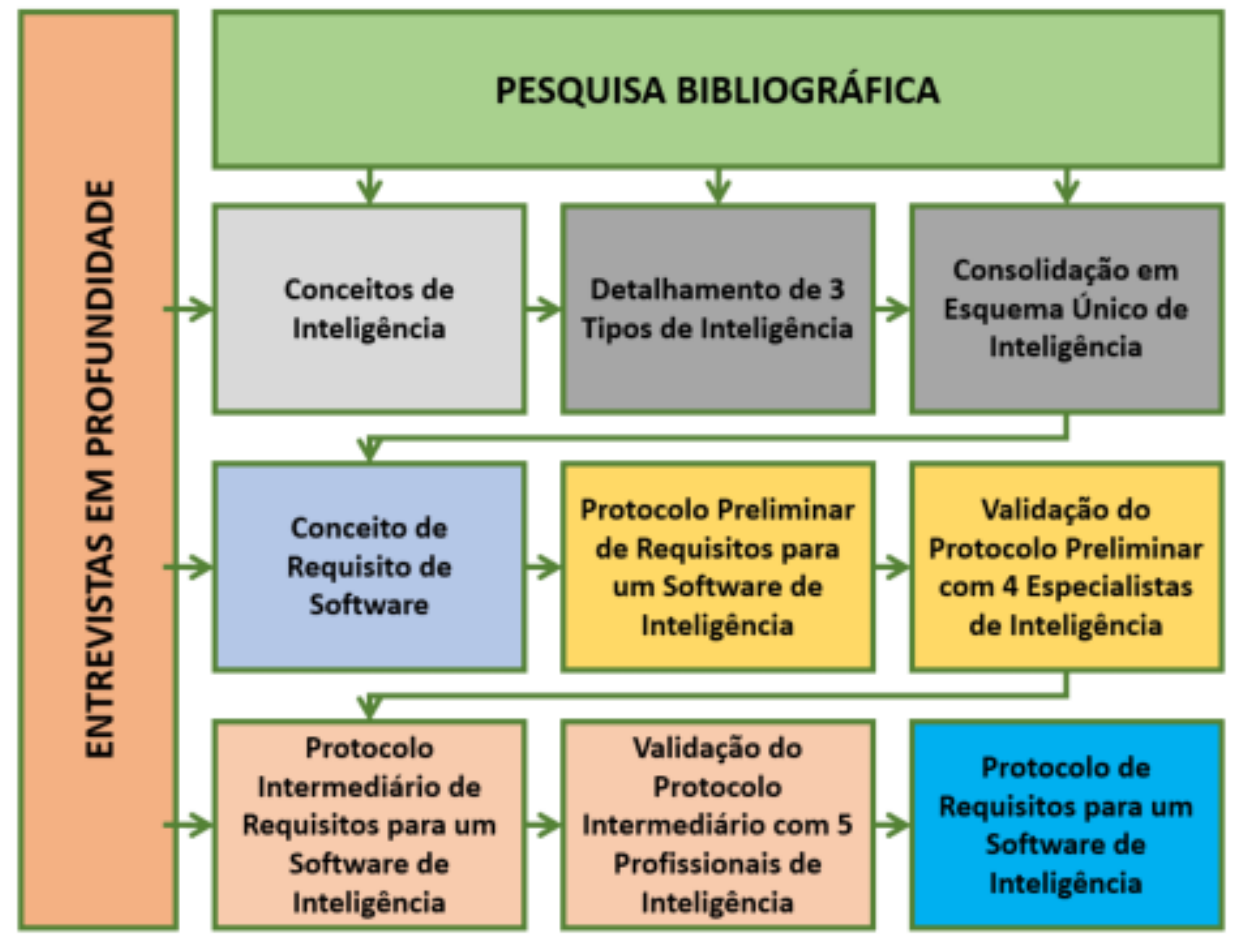

Figura 1 - Desenho de Pesquisa Fonte: os autores

\section{A INTELIGÊNCIA NA LITERATURA ACADÊMICA BRASILEIRA}

O conceito de inteligência não é unanimidade entre pesquisadores (CARDOSO JR e CARDOSO, 2006). Na literatura nacional, encontram-se diferentes nomenclaturas: inteligência empresarial, inteligência empresarial estratégica ou organizacional, inteligência competitiva, inteligência estratégica antecipativa e coletiva, inteligência de negócio e business intelligence.

\subsection{Inteligência Empresarial}

Segundo Degent (1986), a inteligência empresarial focaliza sua atenção no ambiente externo à empresa, particularmente competidores, clientes, tecnologias, políticas governamentais, situação geopolítica e fatores socioeconômicos. Este serviço pode estar orientado por três propósitos: inteligência defensiva, orientada para a obtenção de informações destinadas a evitar surpresas; inteligência passiva, orientada para a obtenção de parâmetros para avaliar o desempenho da empresa; e inteligência ofensiva, orientada para a identificação de oportunidades de negócios. O autor ainda propõe um ciclo do serviço de inteligência empresarial, com as fases gerenciamento, coleta, avaliação, divulgação, utilização e realimentação, e um conjunto de indicadores e áreas a serem monitoradas. Os seguintes autores também abordam o conceito: Rezende (2003); Cavalcanti (2004); Cavalcanti e 
Uma proposta de relação de requisitos funcionais para um software de apoio ao processo de inteligência

Cavalcanti (2005). Entretanto, o próprio conceito de Inteligência Empresarial possui outra abordagem, que não necessariamente uma ramificação, conforme será visto a seguir.

\subsection{Inteligência Empresarial Estratégica}

$\mathrm{O}$ conceito de Inteligência Empresarial Estratégica $\left(\mathrm{IE}^{2}\right)$ é originado da Inteligência Competitiva, e se destina a atender as demandas de informação do planejamento estratégico das organizações (CARDOSO JR, 2005). A $\mathrm{IE}^{2}$ tem a sua aplicação natural no ambiente empresarial, embora também possa ser utilizada com sucesso em organizações governamentais. Consiste em um método ético e legal de conhecer e antever fatos e situações com potencial de afetar um empreendimento, consoante a missão e os objetivos organizacionais. Ela representa uma ferramenta estratégica de análise adaptada a qualquer tipo de problema, sendo aplicável a qualquer setor da atividade humana. A IE $^{2}$ dispõe de forma ordenada e eficaz o trabalho de inteligência a ser realizado pelas organizações empresariais, particularmente as organizações do conhecimento.

\subsection{Inteligência Competitiva}

Para Kahaner (1996), Inteligência competitiva é um programa sistemático de coleta e análise da informação sobre atividades dos concorrentes e tendências gerais dos negócios, visando atingir as metas da empresa. $\mathrm{O}$ autor afirma que inteligência é uma coleção de informações filtradas, destiladas e analisadas. A informação é transformada em algo que possa ser acionável. Segundo o autor, outro termo para inteligência é conhecimento. Tarapanoff (2006) afirma que um sistema de inteligência competitiva permite organizar a coleta de informações e processar seu tratamento e análise, visando a criar uma informação de forte valor agregado, a qual permitirá à empresa criar uma verdadeira inteligência para decisões estratégicas. Entretanto, a autora alerta para os fatores do macro ambiente, como as variáveis políticas, econômicas e sociais. Além do ambiente externo, Tarapanoff fala sobre a importância das informações internas para inteligência competitiva. "A inteligência competitiva deve tomar em consideração também os fatores internos como o conhecimento corporativo, os recursos humanos, os recursos financeiros e, finalmente, a estratégia. Uma boa gestão e uma boa comunicação interna da empresa são fundamentais para manter seu dinamismo e sua eficiência" (TARAPANOFF, 2006). Vieira e Oliveira (2006) afirmam que a Inteligência Competitiva procura levantar questões relacionadas à análise da concorrência, a fim de gerar conhecimento ou variáveis para favorecer a tomada de decisão com foco em expansão de 
Fábio Luiz de Carvalho Rios \& Raquel Janissek-Muniz

mercado e lucro. Os seguintes autores também abordam o conceito: Sapiro (1993); Fuld (1995); Pozzebon, Soares e Dornelas (1997); Vargas e Souza (2001); Marcial e Costa (2001); Pereira, Debiasi e Abreu (2001); Miller (2002); Quandt e Fernandes (2003); Gomes e Braga (2004); Brito, Teixeira e Noleto (2004); Rodriguez y Rodriguez e Fontana (2005); Passos (2005); Gomes (2005); Moresi, Alcântara e Prado (2005); Rodrigues e Toledo (2006); Barbalho (2006); Carvalho et al (2006); Oliveira, Pinto e Salles (2006); Cardoso Jr e Cardoso (2006); Spinola et al (2006), Moori, Kiuma e Kayo (2006); Ruthes, Nascimento e Dergint (2006); Souza (2006); Hoffmann e Chemalle (2006); Machado et al (2006); Valentim (2006); Moresi (2006); Gasparini (2007); Lins e Quandt (2007).

\subsection{Inteligência Estratégica Organizacional}

A Inteligência Estratégica Organizacional não é vista como um processo, mas sim como uma habilidade. Gonçalves e Maciel (2001) entendem inteligência estratégica organizacional como a habilidade da empresa em fazer as pessoas encararem desafios e mudanças o mais facilmente possível, fazendo-as entender que eles são fontes de oportunidades, não de estresse. Desta forma, para Choo (1998) apud Gonçalves e Maciel (2001), inteligência pode ser definida como um modo hábil de processar mudanças, compreender os fatos do ambiente e procurar por novas oportunidades. Se a empresa consegue encontrar e mantiver apenas as pessoas mais preparadas e criativas, a própria mudança será algo natural para elas, uma vez que pessoas criativas podem superar problemas mais facilmente e gastar parte de seu tempo planejando futuras melhorias para a empresa (GONÇALVES e MACIEL, 2001).

\subsection{Inteligência Estratégica Antecipativa e Coletiva (IEAC)}

Por definição, a IEAc é direcionada ao futuro e à antecipação baseada na interpretação de certas informações de tipo sinais fracos ou indícios antecipativos (JANISSEK-MUNIZ et al, 2007). Para Lesca (2003), Inteligência Estratégica Antecipativa e Coletiva (na origem chamada Veille Anticipative Stratégique et Intelligence Collective) é o processo informacional coletivo e proativo através do qual os membros da empresa (ou pessoas solicitadas por ela) captam (percebem, ou provocam, e escolhem), de forma voluntária, e utilizam informações pertinentes relacionadas ao seu ambiente externo e as mudanças que nele podem se produzir. A IEAc é uma forma, para a empresa, de organizar ativamente sua curiosidade em relação às mudanças de seu ambiente, com o objetivo de fortalecer sua competitividade, criar oportunidades de negócios e reduzir riscos e incertezas em geral.

REAd | Porto Alegre - Edição 78 - N 2 - maio/agosto 2014 - p. 425-460 
Uma proposta de relação de requisitos funcionais para um software de apoio ao processo de inteligência

O conceito do Coletivo é empregado propositalmente junto à Inteligência Estratégica Antecipativa [Inteligência Estratégica Antecipativa e Coletiva (IEAc)]. Ou seja, aplicada a um grupo de pessoas que aceitam voluntariamente compartilhar suas capacidades de detectar eventos, de falar sobre eles, de interpretá-los conjuntamente para tirar aprendizados úteis para a ação. As atitudes e aptidões são múltiplas: captar e interpretar sinais novos, decidir como reagir, julgar se novos esquemas de ação ou de raciocínio se tornaram necessários, gerar novas configurações/representações de esquemas e saber escolher qual é a mais criativa dentre as consideradas. Em resumo, Inteligência Coletiva é o que dá sentido ao que o sistema percebe.

A IEAc possui algumas peculiaridades: voltada para o futuro e antecipação de forma explícita; ambiente constituído de atores nomeados (e não de objetos estáticos); interesse para os sinais (indícios) fracos, sem considerar montanhas de informação e sim os pontos singulares nela potencialmente existentes; modo alerta, onde o captador é quem alerta sua hierarquia de forma proativa, e não o contrário onde haveria uma necessidade explícita; frequência de inteligência contínua; particular atenção aos captadores relacionais externos em contato direto com o ambiente (clientes, representantes etc.); atenção especial para as fontes relacionais e informações de primeira mão; interesse portado à criação coletiva de sentido, explicitamente. Os seguintes autores também abordam o conceito: Caron-Fasan e JanissekMuniz (2004); Lesca, Janissek-Muniz e Freitas (2003); Janissek-Muniz et al (2005); Freitas et al (2006); Freitas e Janissek-Muniz (2006); Freitas, Freitas e Gensas (2007); Janissek-Muniz et al (2007); Janissek-Muniz et al (2008).

\subsection{Inteligência de Negócio ou Business Intelligence}

Para Petrini, Freitas e Pozzebon (2006), numa abordagem administrativa, Inteligência de Negócios (BI) pode ser definida como um processo em que os dados internos e externos da empresa são integrados para gerar informação pertinente para o processo de tomada de decisão. Para estes autores, o papel da Inteligência de Negócios é criar um ambiente informacional com processos através dos quais dados operacionais possam ser coletados, tanto dos sistemas transacionais como de fontes externas, e analisados, revelando dimensões estratégicas do negócio. Numa abordagem tecnológica, Inteligência de Negócios é entendida como um conjunto de ferramentas que apoia o armazenamento e análise de informação. $\mathrm{O}$ foco não está no próprio processo, mas nas tecnologias que permitem a gravação, recuperação, manipulação e análise da informação. De acordo com Kudyba e Hoptroff (2001)

REAd | Porto Alegre - Edição 78 - N 2 - maio/agosto 2014 - p. 425-460 
Fábio Luiz de Carvalho Rios \& Raquel Janissek-Muniz

apud Petrini, Freitas e Pozzebon (2006), Inteligência de Negócios é como uma tecnologia de repositório de dados que permite aos usuários extrair dados (demográficos e transacionais) e gerar relatórios estruturados que podem ser distribuídos nas empresas através das redes internas.

Os seguintes autores também abordam o conceito: Rodrigues e Nunes (2001); Petrini, Pozzebon e Freitas (2004); Rauter e Vanti (2005); Petrini, Freitas e Pozzebon (2006); Reginato e Nascimento (2006); Sguario dos Reis e Angeloni (2006); Petrini, Pozzebon e Meirelles (2007); Santiago Jr e Costa de Mendonça (2007).

\subsection{Diferenças e Convergências nos Conceitos de Inteligência}

Observando os conceitos de inteligência apresentados, percebe-se que não há consenso em relação ao foco de atuação da inteligência aplicada ao ambiente de negócios. Enquanto Lesca (2003) e Kahaner (1996) focam mais o contexto competitivo, os concorrentes e o ambiente externo em geral, representado por atores cujas decisões podem interferir diretamente na organização, Tarapanoff (2006) salienta a importância do macro ambiente e das informações internas. Por sua vez, Petrini, Freitas e Pozzebon (2006) focam inteligência como sendo uma tecnologia que associa dados internos e externos selecionados e armazenados propositalmente, enquanto Vieira e Oliveira (2006) entendem inteligência com foco concorrencial.

Desta forma, os enfoques em inteligência podem ser classificados em:

- “ambiente concorrencial", ou seja, preocupa-se em monitorar os movimentos dos concorrentes;

- “ambiente externo", além dos concorrentes, a inteligência monitora movimentos de mercado, o que inclui clientes, fornecedores, governo e demais movimentos;

- "ambiente externo e interno" inclui também a análise das informações internas da organização.

Para uma melhor compreensão, segue síntese sobre as abordagens consultadas: 
Uma proposta de relação de requisitos funcionais para um software de apoio ao processo de inteligência

Quadro 3 - Quadro-resumo dos conceitos inteligência por enfoque

\begin{tabular}{|c|c|c|c|}
\hline $\begin{array}{ll}\text { Referência } & \text { Abordagem } \\
\end{array}$ & $\begin{array}{c}\text { Apenas } \\
\text { concorrência }\end{array}$ & $\begin{array}{l}\text { Ambiente } \\
\text { Externo }\end{array}$ & $\begin{array}{l}\text { Ambiente } \\
\text { Externo e } \\
\text { Interno }\end{array}$ \\
\hline $\begin{array}{l}\text { Quandt e Fernandes (2003); Vieira e Oliveira } \\
\text { (2006) }\end{array}$ & $\begin{array}{l}\text { Inteligência } \\
\text { Competitiva }\end{array}$ & & \\
\hline $\begin{array}{l}\text { Sapiro (1993); Fuld (1995); Pozzebon, Soares e } \\
\text { Dornelas (1997); Vargas e Souza (2001); Marcial e } \\
\text { Costa (2001); Miller (2002); Gomes e Braga } \\
\text { (2004); Brito, Teixeira e Noleto (2004); Passos } \\
\text { (2005); Gomes (2005); Moresi, Alcântara e Prado } \\
\text { (2005); Rodrigues e Toledo (2006); Oliveira, Pinto } \\
\text { e Salles (2006); Cardoso Jr e Cardoso (2006); } \\
\text { Spinola et al (2006), Moori, Kiuma e Kayo (2006); } \\
\text { Ruthes, Nascimento e Dergint (2006); Souza } \\
\text { (2006); Hoffmann e Chemalle (2006); Machado et } \\
\text { al (2006); Valentim (2006); Moresi (2006); } \\
\text { Gasparini (2007); Lins e Quandt (2007) }\end{array}$ & & $\begin{array}{l}\text { Inteligência } \\
\text { Competitiva }\end{array}$ & \\
\hline Cardoso Jr (2005) & & $\begin{array}{l}\text { Inteligência } \\
\text { Empresarial } \\
\text { Estratégica }\end{array}$ & \\
\hline $\begin{array}{l}\text { Degent (1986); Cavalcanti (2004); Cavalcanti e } \\
\text { Cavalcanti (2005) }\end{array}$ & & $\begin{array}{l}\text { Inteligência } \\
\text { Empresarial }\end{array}$ & \\
\hline $\begin{array}{l}\text { Caron-Fasan e Janissek-Muniz (2004); Lesca, } \\
\text { Janissek-Muniz e Freitas (2003); Janissek-Muniz } \\
\text { et al (2005); Freitas et al (2006); Freitas e Janissek- } \\
\text { Muniz (2006); Freitas, Freitas e Gensas (2007); } \\
\text { Janissek-Muniz et al (2007); Janissek-Muniz et al } \\
\text { (2008) }\end{array}$ & & $\begin{array}{l}\text { Inteligência } \\
\text { Estratégica } \\
\text { Antecipativa }\end{array}$ & \\
\hline $\begin{array}{l}\text { Rodrigues e Nunes (2001); Petrini, Pozzebon e } \\
\text { Freitas (2004); Rauter e Vanti (2005); Petrini, } \\
\text { Freitas e Pozzebon (2006); Reginato e Nascimento } \\
\text { (2006); Sguario dos Reis e Angeloni (2006); } \\
\text { Petrini, Pozzebon e Meirelles (2007); Santiago Jr e } \\
\text { Costa de Mendonça (2007) }\end{array}$ & & & $\begin{array}{l}\text { Inteligência de } \\
\text { Negócio / } \\
\text { Business } \\
\text { Intelligence }\end{array}$ \\
\hline $\begin{array}{l}\text { Pereira, Debiasi e Abreu (2001); Rodriguez y } \\
\text { Rodriguez e Fontana (2005); Barbalho (2006); } \\
\text { Carvalho et al (2006); Tarapanoff (2006) }\end{array}$ & & & $\begin{array}{l}\text { Inteligência } \\
\text { Competitiva }\end{array}$ \\
\hline Rezende (2003) & & & $\begin{array}{l}\text { Inteligência } \\
\text { Empresarial }\end{array}$ \\
\hline Gonçalves e Maciel (2001) & & & $\begin{array}{c}\text { Inteligência } \\
\text { Estratégica } \\
\text { Organizacional }\end{array}$ \\
\hline
\end{tabular}

Fonte: do autor

Percebe-se que a maior parte dos autores de Inteligência Competitiva e Inteligência Empresarial, assim como a totalidade dos autores de Inteligência Empresarial Estratégica e Inteligência Estratégica Antecipativa e Coletiva, entendem o conceito de inteligência como sendo uma metodologia com foco nas informações externas das organizações, não apenas em 
Fábio Luiz de Carvalho Rios \& Raquel Janissek-Muniz

monitoramento concorrencial e tampouco olhando apenas informações internas. Nesta linha de análise em relação ao foco concorrencial, somente externo ou interno e externo, pode-se entender Inteligência Competitiva, Inteligência Estratégica Antecipativa e Coletiva, Inteligência Empresarial e Inteligência Empresarial Estratégica como sinônimos para fins deste trabalho. Segundo Rios, Strauss, Brodbeck e Janissek-Muniz (2011), inteligência de um modo geral pode representar um conjunto de ações para localizar, obter, escolher, associar e usar de forma pertinente o conhecimento oriundo do ambiente da empresa. Pode-se entender Inteligência Competitiva, Inteligência Estratégica Antecipativa, Inteligência Empresarial e Inteligência Empresarial Estratégica como conceitos vizinhos (RIOS, STRAUSS, BRODBECK E JANISSEK-MUNIZ, 2011).

Assim, optamos por eleger três tipos de inteligência com foco em ambiente externo, por entender que é dele que podem surgir, em graus diferentes de intensidade, as principais mudanças que podem ter um impacto significativo para o negócio de uma organização. Assim, optamos pela Inteligência Competitiva, em função do grande número de vezes que é citada em artigos e livros. Para tal, foi escolhida a referência de Elisabeth Gomes. Em segundo lugar, foi escolhida a Inteligência Estratégica Antecipativa e Coletiva de Humbert Lesca, em função de sua originalidade e foco privilegiado e declarado em alvo do ambiente externo. O último tipo deveria ser escolhido entre o de Inteligência Empresarial ou o de Inteligência Empresarial Estratégica. Entretanto, Inteligência Competitiva, ou seus autores, foram citados nos artigos analisados junto com Inteligência Empresarial e com Inteligência Empresarial Estratégica, dando a entender que são sinônimos. Há, de fato, certa confusão no uso dos termos. Ao mesmo tempo, o esquema original de Degent (1986) sobre Inteligência Empresarial foi considerado um tanto antigo para fazer parte deste estudo. Desta forma, elegeu-se uma segunda proposta de Inteligência Competitiva, a do americano Leonard Fuld, que possui abordagem distinta da anterior (Gomes). Para melhor esclarecer as peculiaridades de cada tipo, serão detalhados a seguir os ciclos e as práticas destes três tipos escolhidos.

\subsubsection{Inteligência Competitiva segundo Gomes}

Gomes (2008) sugere atividades necessárias para preparar a empresa para realização do processo de inteligência:

REAd | Porto Alegre - Edição 78 - N 2 - maio/agosto 2014 - p. 425-460 
Uma proposta de relação de requisitos funcionais para um software de apoio ao processo de inteligência

a) Comunicação e Sensibilização dos colaboradores da empresa, conscientizando a empresa da importância da informação competitiva;

b) Capacitação da Equipe de IC, formando os colaboradores que irão atuar direta e indiretamente nesta área;

c) Definição da missão e dos objetivos da Inteligência Competitiva, conscientizando a respeito dos obstáculos aparecerão, em maior ou menor escala, e que suplantá-los, será o grande desafio; identificar os obstáculos e traçar rotas alternativas, ajudará a organização a alcançar a missão definida;

d) Estruturação da área e definição da equipe necessária para conduzir este processo, buscando equipes multifuncionais com competências e habilidades específicas para executar os sub-processos de IC;

e) Definição e implantação de sistemas de informação, identificando tecnologias que possam suportar o processo de IC, permitindo a entrega de produtos de inteligência de forma eficaz e segura.

O processo de IC (Figura 2) é apresentado por Gomes (2008) conforme como forma esquemática de sub-processos, que são: Identificação de Necessidades de Inteligência, Identificação de necessidades de Informação, Coleta e armazenamento de informações, Análise de informações, Disseminação e Avaliação dos produtos de inteligência.

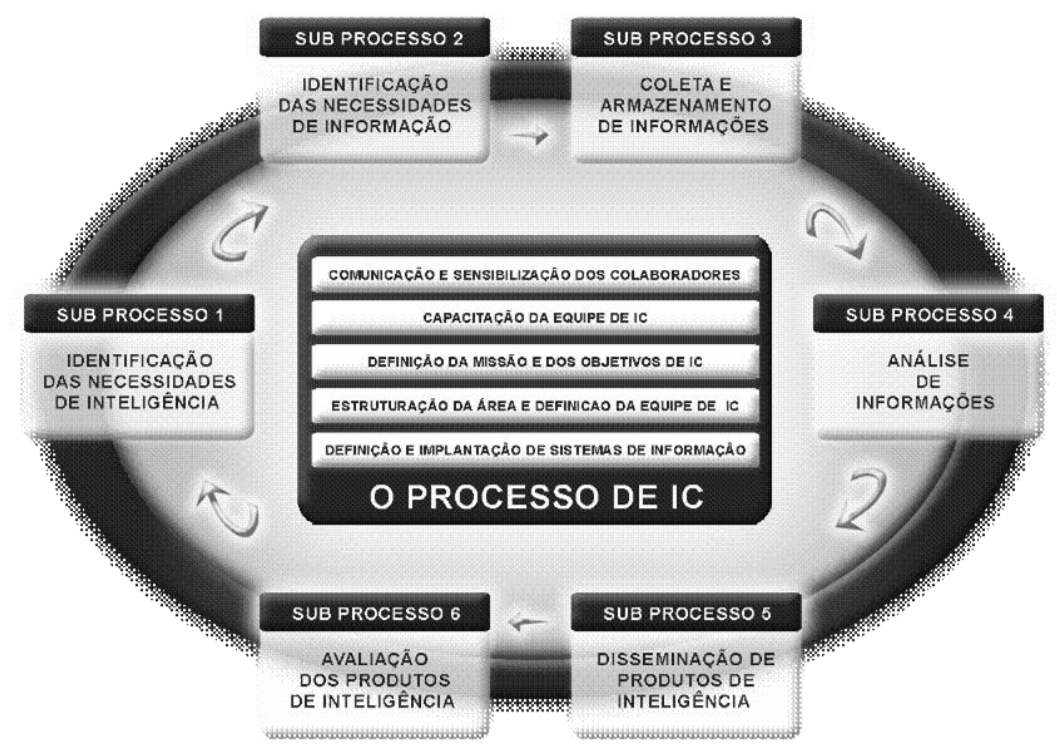

Figura 2 - Ciclo de Inteligência Competitiva Fonte: Gomes (2008) 


\subsubsection{Inteligência Competitiva segundo Fuld}

Para Fuld (2006), inteligência competitiva é a habilidade de enxergar através ou ficar à frente de seus competidores. É a muda e escondida chave para o sucesso. É a forma de conhecer o pensamento estratégico de um cliente, a estrutura de custo de um rival ou os planos de um concorrente para o lançamento de um novo produto. Tanto quanto em um jogo de xadrez, é necessário pensar muitos lances na frente de um rival. Pois isto é o que inteligência competitiva pode oferecer para as organizações.

A preparação para a construção de um processo de Inteligência competitiva é tudo. Para garantir uma boa análise, faz-se necessário preparar as questões e criar um guia detalhado para o atingimento dos objetivos (FULD, 1995). Para o autor, existem nove passos que precisam ser realizados antes do início da geração de inteligência por uma organização:

- Definição da questão: é preciso ter convicção de que o analista de inteligência e seu cliente interno estão alinhados em relação ao que esperam conhecer;

- Aprender sobre a indústria: é preciso conhecer detalhadamente tudo sobre a indústria da empresa, do produto ou do serviço que será estudado;

- Conhecer as fontes: ao invés de ir diretamente às fontes mais comuns, deve se perguntar sobre quais fontes podem ser mais eficazes e possivelmente mais produtivas;

- Conduzir pesquisa em literatura: nenhuma pesquisa em literatura deve ser feita sem o apoio de uma base de dados. Quando usada corretamente, uma base de dados pode apoiar muito na identificação de informações importantes;

- Organizar uma biblioteca: esta biblioteca deve apresentar uma série de nomes de especialistas com contatos e inúmeras referências do seu alvo de acompanhamento;

- Destrinchar artigos: muitas vezes o artigo não traz a informação completa, mas suas referências bibliográficas e os nomes citados podem sinalizar o caminho a seguir;

- Preparar a estratégia: uma vez que as fontes de monitoramento e a lista de especialistas estão prontas, comece a compará-las a fim de identificar em quem ir primeiro e quais são as mais confiáveis;

- Começar o processo de entrevistas: não se deve aguardar toda a biblioteca ficar pronta para se dar início a pesquisa. Durante as entrevistas outras fontes de informação e outros sinalizadores serão identificados para a produção de inteligência; 
Uma proposta de relação de requisitos funcionais para um software de apoio ao processo de inteligência

- Conduzir um debriefing e armazenar o conhecimento: depois que o resultado estiver pronto, deve ser feita uma comparação com demais estudos anteriores, a fim de se perceber oportunidades de melhoria ou complementos.

O ciclo de inteligência competitiva de Fuld envolve cinco passos consecutivos:

1. Planejamento e direção

2. Coleta de informações publicadas

3. Coleta de informações primárias

4. Análise e produção

5. Relatório e informação

A Figura 3 apresenta o ciclo de inteligência competitiva proposto por Fuld.

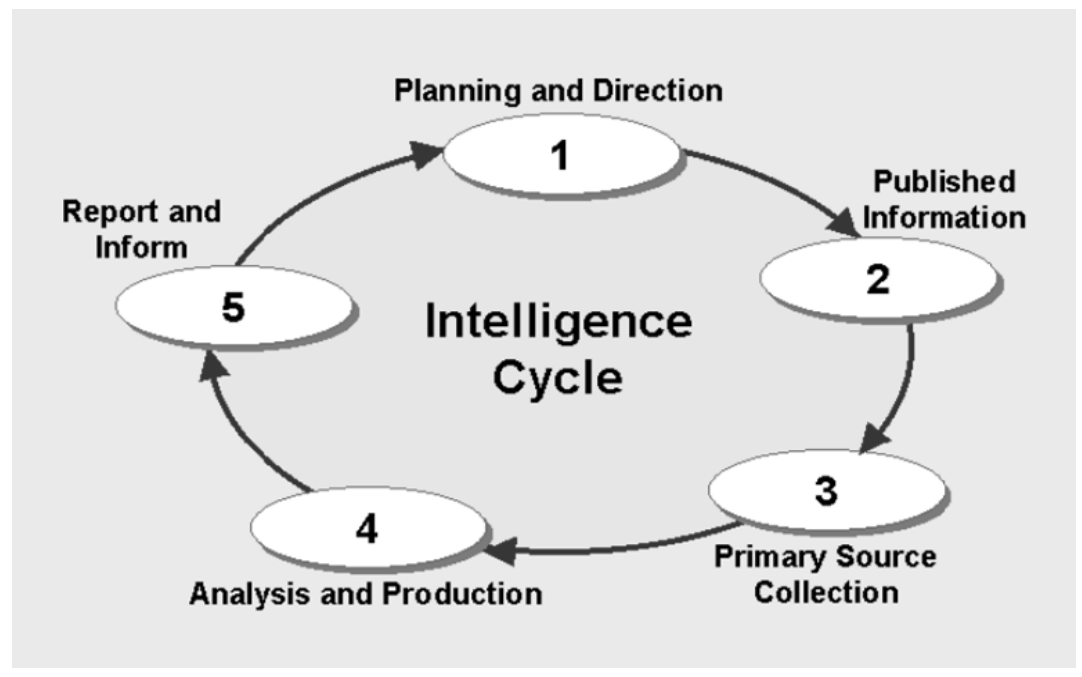

Figura 3 - Ciclo de Inteligência

Fonte: Fuld (2008)

Para Fuld (2008), eliminar alguma das etapas fará resultar em análise imperfeita ou decisão equivocada.

\subsubsection{Inteligência Estratégica Antecipativa e Coletiva}

Na origem chamada Veille Anticipative Stratégique, Inteligência Estratégica Antecipativa é o processo informacional coletivo e contínuo pelo qual um grupo de indivíduos busca (de forma voluntária) e utiliza informações antecipativas relacionadas às mudanças susceptíveis de se produzirem no ambiente exterior da empresa, com o objetivo de criar oportunidades de negócios e de reduzir riscos e incertezas em geral (LESCA, 2003). Janissek-Muniz, Lesca e 
Fábio Luiz de Carvalho Rios \& Raquel Janissek-Muniz

Freitas (2007) consideram que Inteligência Estratégica Antecipativa (IEA) engloba diversos tipos de inteligência específicos, tais como a Inteligência Tecnológica (produtos, serviços, inovação), a Inteligência Competitiva (concorrentes, competidores), Inteligência Comercial (clientes), Inteligência Territorial (relacionada ao Estado), Inteligência Legal (leis, jurisprudência), Inteligência Social, entre outras.

A importância e potencial utilidade da abordagem sobre dados aparentemente inúteis ou mesmo sem significado, quando avaliados de forma isolada, são ressaltados por JanissekMuniz, Freitas e Lesca (2007), conforme Figura 4. De fato, a visão que se pode ter em relação a certo tema ou situação - quando nossa atenção se concentra habitualmente em dados comuns trafegando na organização - muda completamente se tivermos uma sistemática próativa e coletiva de organização, rastreamento e leitura de dados singulares. A IEAc não nega a importância do rastreamento automatizado de muitas informações, mas explicitamente elege sinais fracos ou indícios antecipativos como norteadores de sua abordagem.

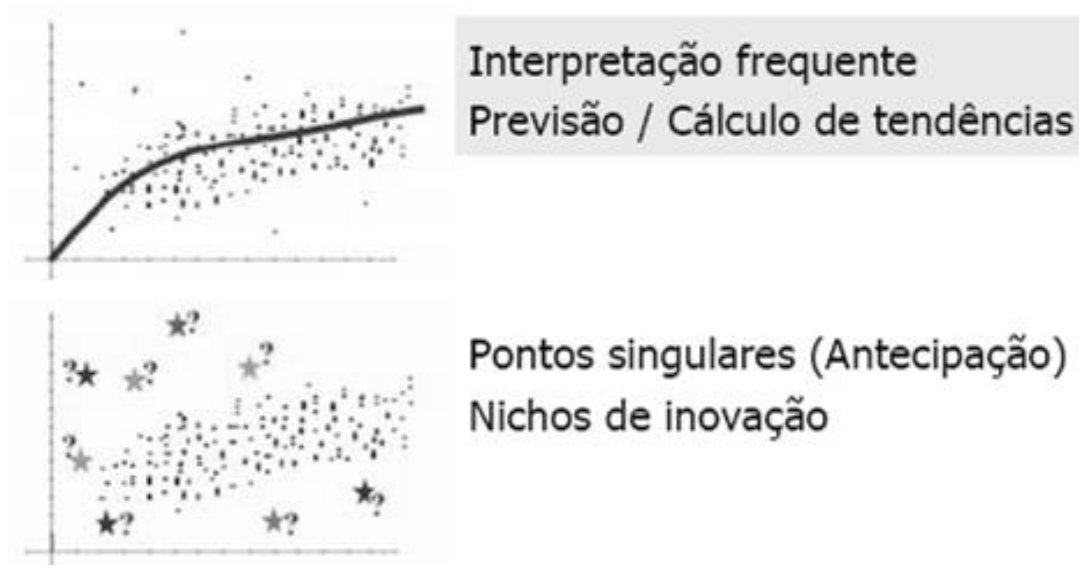

Figura 4 - Informações Dispersas \& Sinais Fracos Fonte: Janissek-Muniz (2008)

A coletividade em IEAc é fundamental, pois a pró-atividade na pesquisa e uso de informações, não tem como ser uma atividade individual. Para Janissek-Muniz, Lesca e Freitas (2007), é necessária a intervenção de diversos membros da empresa, cada deles em função de suas atividades, experiências e competências. Este processo engloba tanto a definição de alvo, captação, seleção como, e principalmente, a fase de interpretação das informações. São fases delicadas que necessitam a mobilização de experiências diversas, razão pela qual que a IEA é apresentada alinhada ao conceito de inteligência coletiva. Existe Inteligência Coletiva, ou seja, de um grupo de indivíduos, quando os sinais observados no ambiente, sua seleção e seus relacionamentos são objeto de um trabalho coletivo, onde 
Uma proposta de relação de requisitos funcionais para um software de apoio ao processo de inteligência

indivíduos comunicam e interagem apropriadamente, dentro do respeito de certas regras de comportamento do trabalho em grupo (LESCA, JANISSEK-MUNIZ e FREITAS, 2003).

Através da captação de informações antecipativas e com as características bem específicas (pouco repetitivas, incertas, ambíguas, fragmentadas e mesmo contraditórias) está o conceito dos sinais fracos ou indícios antecipativos (JANISSEK-MUNIZ, FREITAS e LESCA, 2007). Este tipo de informação pode ser captado em elementos de informação dispersos e de ocorrência variada, aos quais frequentemente são descartadas ou deixadas de lado. Entretanto, estes sinais fracos combinados com outros podem induzir a certas percepções e a inferir ações a realizar.

Além da coletividade e da antecipação, o ambiente observado é aquele externo à empresa, direto ou indireto (LESCA, 2003; JANISSEK-MUNIZ, 2004), o qual deve ser conhecido e do qual serão coletadas as informações antecipativas. Lesca, Janissek-Muniz e Freitas (2003) entendem ambiente como o ambiente de negócios da empresa, sobretudo externo, concretizado por atores (SHAW, 1999 apud LESCA, JANISSEK-MUNIZ e FREITAS, 2003) que, através de suas decisões, podem impactar fortemente o negócio da empresa. Esses atores podem ser fornecedores, parceiros, concorrentes, patrocinador, clientes, laboratórios, organismos, homens políticos, entre outros. Trata-se de um conjunto de pessoas que podem gerar maior ou menor interesse em função das decisões que tomarão. A IEAc não se interessa apenas por atores conhecidos. Interessa-se, sobretudo, pelos atores potenciais e/ou indiretos, aqueles que atualmente não são atores diretos, mas poderão vir a ser, talvez até subitamente. Um novo concorrente significa uma ameaça. Um novo cliente, patrocinador, fornecedor ou parceiro, uma oportunidade. A metáfora do radar, utilizada para conceituar a IEAc, na verdade não significa um radar único, mas vários radares, tantos quanto possível: radares sobre concorrentes, clientes, fornecedores, entre outros (JANISSEK-MUNIZ, LESCA e FREITAS, 2007).

Janissek-Muniz, Lesca e Freitas (2007) afirmam que a IEA busca, através de métodos próprios desenvolvidos pela equipe L.E.SCA (http://www.veille-strategique.org), fornecer uma representação do ambiente pertinente presente e elementos que permitam inferir mudanças neste ambiente, objetivando apoiar o processo decisório e agir de forma rápida e no momento certo. O método L.E.SCAnning (Figura 5) é uma metodologia original, composta por 9 etapas: domínio de aplicação, especificação de alvo, coleta, seleção de informações, repasse de informações, memória, criação coletiva de sentido, difusão e animação. 
Fábio Luiz de Carvalho Rios \& Raquel Janissek-Muniz

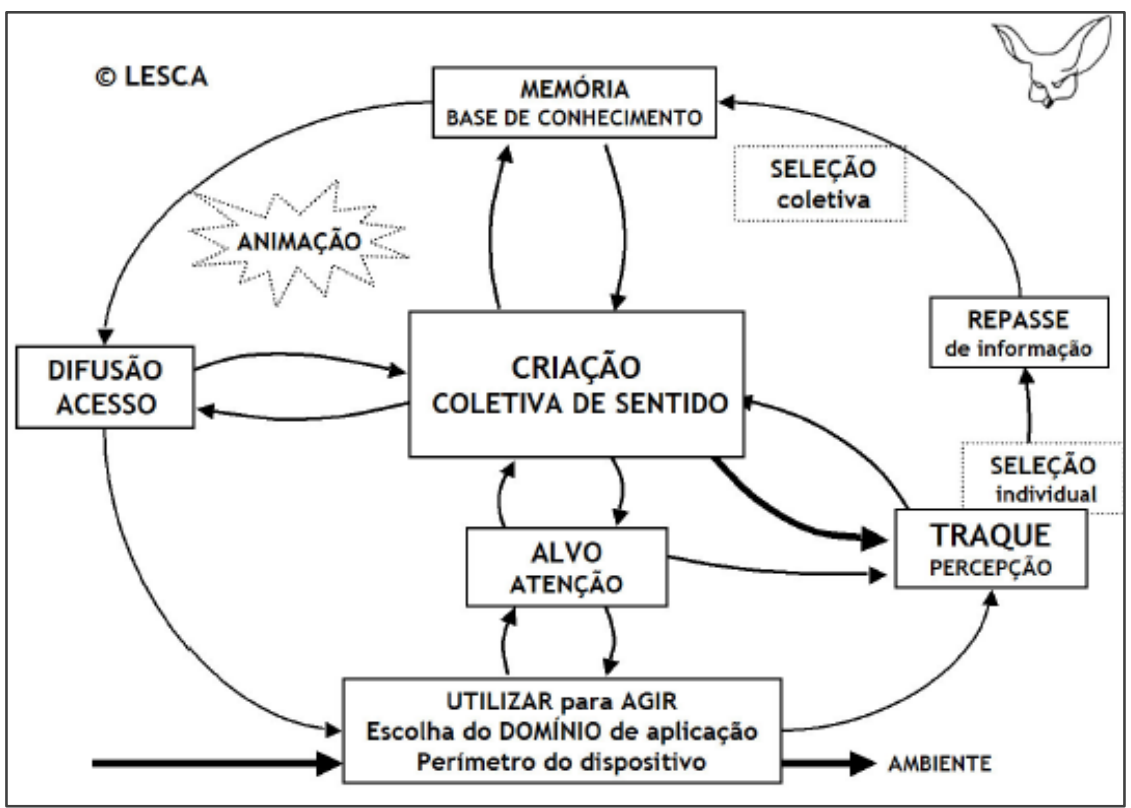

Figura 5 - Método L.E.SCAnning

Fonte: Janissek-Muniz, Lesca e Freitas (2007)

O método L.E.SCAnning começa na escolha de um domínio de aplicação, também chamado de perímetro do dispositivo, ou seja, qual a área da empresa sobre a qual deverá se agir de forma prioritária. Em seguida encontra-se a fase de especificação de alvo, etapa que demanda atenção direcionada por parte da empresa, que deverá delimitar os temas, atores e fontes de informação prioritária.

De acordo com Janissek-Muniz, Lesca e Freitas (2007), a etapa seguinte, chamada de coleta de informações, foca em buscar informações relativas aos atores e aos temas identificados na fase precedente ou a partir de alvos identificados a posteriori (JANISSEKMUNIZ, 2004). A execução desta etapa se dá através dos captadores, colaboradores da empresa que terão o objetivo de selecionar informações que auxiliem no entendimento deste ambiente. A coleta somente poderá ser eficaz se o procedimento de repasse de informações estiver organizado. Esta fase tem como objetivo organizar a circulação de fluxos internos à empresa, assim como também aqueles provenientes do exterior. A fase de repasse de informações estaria incompleta sem a implantação de um procedimento de armazenamento de informações, que permite divulgar ao coletivo as informações coletadas, de forma que este possa selecioná-las a partir de conhecimentos diversos do coletivo (JANISSEK-MUNIZ, LESCA e FREITAS, 2007).

As informações selecionadas são analisadas coletivamente na fase de criação coletiva de sentido. Esta etapa possui o objetivo de atribuir sentido às informações e gerar valor agregado. De acordo com Janissek-Muniz, Lesca e Freitas (2007), esta etapa conduz a uma REAd | Porto Alegre - Edição 78 - N² 2 - maio/agosto 2014 - p. 425-460 
Uma proposta de relação de requisitos funcionais para um software de apoio ao processo de inteligência

alternativa. Se as informações analisadas são suficientemente explícitas, esta fase permite a tomada de decisões e a ação no ambiente de competição. Entretanto, se as análises não permitem compreender o futuro ambiente da empresa, esta deverá continuar coletando informações e, talvez, mudar o alvo.

A IEAc, por ser um processo complexo implicando diversos atores, demanda a intervenção de competências distintas e complementares, cujos interesses e motivações podem mesmo ser contraditórios (CARON-FASAN e JANISSEK-MUNIZ, 2004). Desta forma, a atividade de IEAc estabelece-se como um processo necessariamente coletivo, e também contínuo, dinâmico e evolutivo, exigindo uma formação e um acompanhamento particulares.

\subsubsection{Consolidação de Inteligência a partir dos tipos de Inteligência Estudados}

A consolidação em esquema único de Inteligência foi baseada na descrição dos objetivos e atividades de cada etapa dos tipos selecionados. Os três tipos de inteligência abordados nesta revisão, apesar de possuírem etapas com nomes distintos, reforçam sua coerência ao apresentarem a mesma lógica em planejar o que se espera identificar em termos de inteligência, reunir informações, analisá-las e disseminá-las aos tomadores de decisão. Apenas o tipo de Gomes contempla uma etapa a mais, a fim de garantir a avaliação do processo.

A etapa de Animação da IEAc foi agrupada na etapa de Planejamento da Demanda de Inteligência pois, assim como a atividade de comunicação e sensibilização dos colaboradores de Gomes, tem como objetivo mostrar a importância do processo de inteligência e mantê-lo "vivo" dentro da organização. Em outras palavras, esta etapa apoia o Planejamento da Demanda de Inteligência uma vez que, conforme afirma Fuld (2008), para definir o que se espera de um processo de inteligência, é preciso trabalhar lado a lado aos tomadores de decisão. Se não houver um animador que possa liderar, comunicar e sensibilizar a organização, inclusive seus tomadores de decisão, dificilmente será possível planejar a demanda de inteligência.

As etapas de Repasse de Informações, Seleção de Informações e Armazenamento de Informações, além de Criação Coletiva de Sentido, foram agrupadas em Análise e Produção de Inteligência. Por mais que Repasse, Seleção e Armazenamento possam parecer funções da coleta, estas atividades já dão início à avaliação das informações e a identificação de suas relações, permitindo a geração de inteligência. Todas as demais etapas de todos os tipos de 
Fábio Luiz de Carvalho Rios \& Raquel Janissek-Muniz

inteligência revisados não serão explicadas porque seus nomes e descrições são explícitos para permitir o agrupamento de suas atividades. Sendo assim, baseado na descrição dos objetivos e atividades de cada etapa dos processos, foi possível identificar quais etapas, apesar de identificadas diferentemente, apresentam o mesmo escopo. Desta forma, as atividades dos diferentes tipos foram agrupadas por objetivos, descritos no início deste trabalho.

O quadro 4 agrupa os três ciclos de inteligência:

Quadro 4 - Agrupamento das etapas do processo de inteligência

\begin{tabular}{|c|c|c|c|}
\hline Etapas Agrupadas (Autor) & $\begin{array}{c}\text { Inteligência } \\
\text { Competitiva } \\
\text { (Elisabeth Gomes) }\end{array}$ & $\begin{array}{l}\text { Inteligência } \\
\text { Competitiva } \\
\text { (Leonard Fuld) }\end{array}$ & $\begin{array}{l}\text { Inteligência } \\
\text { Estratégica } \\
\text { Antecipativa } \\
\text { (Humbert Lesca) }\end{array}$ \\
\hline \multirow{3}{*}{$\begin{array}{c}\text { Planejamento da Demanda de } \\
\text { Inteligência }\end{array}$} & $\begin{array}{l}\text { Identificação de } \\
\text { Necessidades de } \\
\text { Inteligência }\end{array}$ & \multirow{3}{*}{ Planejamento e Direção } & Animação \\
\hline & \multirow{2}{*}{$\begin{array}{l}\text { Identificação de } \\
\text { necessidades de } \\
\text { Informação }\end{array}$} & & $\begin{array}{l}\text { Escolha do Domínio de } \\
\text { Aplicação }\end{array}$ \\
\hline & & & Definição de Alvo \\
\hline \multirow[b]{2}{*}{$\begin{array}{l}\text { Coleta de Informações para } \\
\text { Produção de Inteligência }\end{array}$} & \multirow{2}{*}{$\begin{array}{c}\text { Coleta e } \\
\text { armazenamento de } \\
\text { informações }\end{array}$} & $\begin{array}{c}\text { Coleta de Informações } \\
\text { Publicadas } \\
\end{array}$ & \multirow[b]{2}{*}{$\begin{array}{l}\text { Coleta e Captação de } \\
\text { Informações }\end{array}$} \\
\hline & & $\begin{array}{l}\text { Coleta de Informações } \\
\text { Primárias }\end{array}$ & \\
\hline \multirow{4}{*}{$\begin{array}{l}\text { Análise e Produção de } \\
\text { Inteligência }\end{array}$} & \multirow{4}{*}{ Análise de informações } & \multirow{4}{*}{ Análise e Produção } & $\begin{array}{c}\text { Repasse de } \\
\text { Informações } \\
\end{array}$ \\
\hline & & & Seleção de Informações \\
\hline & & & $\begin{array}{c}\text { Armazenamento de } \\
\text { Informações } \\
\end{array}$ \\
\hline & & & $\begin{array}{l}\text { Criação Coletiva de } \\
\text { Sentido }\end{array}$ \\
\hline $\begin{array}{l}\text { Disseminação de Relatório de } \\
\text { Inteligência }\end{array}$ & $\begin{array}{l}\text { Disseminação de } \\
\text { produtos de inteligência }\end{array}$ & Relatório e Informação & Difusão e Acesso \\
\hline $\begin{array}{c}\text { Avaliação de Relatório de } \\
\text { Processo de Inteligência }\end{array}$ & $\begin{array}{l}\text { Avaliação dos produtos } \\
\text { de inteligência }\end{array}$ & - & - \\
\hline
\end{tabular}

Fonte: do autor

Uma vez finalizada a consolidação dos três tipos de inteligência, faz-se necessário identificar atividades que possam se tornar requisitos funcionais de software, cuja teoria será abordada na próxima seção.

\section{CONCEITO DE REQUISITO DE SOFTWARE}

Quanto mais rápido um negócio puder adaptar seus processos e os sistemas de informação que o suportam, mais preparado estará para enfrentar eventos de concorrência no mercado. Segundo Azevedo Jr e Campos (2008), o levantamento de requisitos é a etapa do 
Uma proposta de relação de requisitos funcionais para um software de apoio ao processo de inteligência

desenvolvimento de sistemas de informação responsável por identificar e modelar as necessidades do negócio a serem atendidas pelos sistemas de informação, e é, portanto, uma atividade cada vez mais relevante em um dinâmico cenário.

De acordo com Zanlorenci e Burnett (1998), requisito pode ser definido como "algo que um cliente necessita". Do ponto de vista de um desenvolvedor de software, requisito também pode ser definido como algo que necessita ser modelado e implementado. No contexto de sistemas, requisitos são fenômenos do ambiente que o software deve executar, uma condição capaz de resolver um problema ou atingir um objetivo; uma condição ou capacidade que deve ser encontrada e constar em um sistema ou seu componente, para satisfazer um contrato, padrão, especificação ou outro documento imposto formalmente; uma representação documentada de uma condição ou capacidade.

Paula Filho (2001) afirma que a engenharia de requisitos é formada por um conjunto de técnicas empregadas para levantar, detalhar, documentar e validar os requisitos de um produto de software. Assim, é possível definir a engenharia de requisitos como um campo da engenharia de software que visa à aplicação de técnicas de engenharia em métodos de análise de requisitos, que efetua a ligação entre a necessidade de informatização de processos e o projeto do software que atenderá a tais necessidades. Para Zanlorenci e Burnett (1998), os requisitos caracterizam-se sob duas formas fundamentais:

1) Por requisitos funcionais, entendem-se os fenômenos ambientais referentes ao negócio e domínio da aplicação que se queira conhecer e estudar, ou seja, o que fazer. São escritos do ponto de vista do cliente. São expressos em linguagem natural, diagrama informal ou usando alguma notação que é apropriada para o entendimento do problema;

2) Por requisitos não funcionais ou especificações, entendem-se as especificações técnicas de como melhor adequar a solução do problema para responder ao cliente. São especificações que podem ser expressas como um modelo abstrato do sistema. Pode ser um modelo matemático ou baseado em notações gráficas, tais como diagrama de fluxo de dados, hierarquia de classes de objetos e, de preferência em linguagens de representação formal, que podem gerar código fonte e objeto diretamente.

Entretanto, de acordo com Krafta (2007), muitos dos fracassos de empresas em relação aos seus projetos de TI podem ser explicados pela lacuna existente entre a expectativa dos usuários em relação a um sistema de informação e quanto esta expectativa é de fato atendida. O fato é que esta lacuna também pode ser traduzida por uma falta de alinhamento entre o que usuários idealizam e necessitam em um sistema que apoie suas atividades e o que os 
desenvolvedores percebem sobre este mesmo aspecto (LAI, 2000 apud KRAFTA, 2007). Desta forma, um processo para a definição de requisitos faz-se fundamental a fim de evitar que o problema de falta de alinhamento aconteça.

O processo de extração de requisitos requer uma análise criteriosa da organização, compreendendo: a definição do alvo e da abrangência do domínio da aplicação, o entendimento do foco no problema a resolver (o quê, para quê e para quem), a identificação de processos do negócio e, principalmente o conhecimento da informação do cliente relativa às suas necessidades ou desejos e exigências (ZANLORENCI e BURNETT, 1998). Embora ainda não exista uma solução à prova de falhas, para Lopes, Majdenbaum e Audy (2003) um processo sólido de engenharia de requisitos é a melhor solução existente para assegurar a especificação de um software de acordo com as necessidades do cliente.

Segundo Fernandes da Silva (2006), o processo de definição de requisitos pode ser definido por três atividades: elicitação, modelagem e análise. Geralmente, estas atividades ocorrem simultânea e incrementalmente, num processo evolutivo que dura todo o processo de desenvolvimento de software.

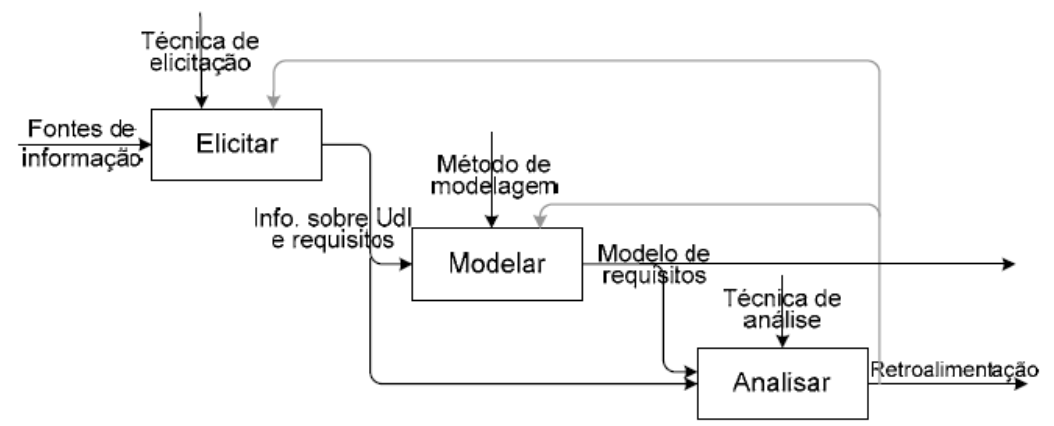

Figura 6 - Processo de definição de requisitos

Fonte: Fernandes da Silva (2006)

Elicitação - conjunto de técnicas para descobrir os requisitos do sistema a ser desenvolvido. As principais técnicas são: leitura de documentos, observação, entrevistas, reuniões, questionários, antropologia, participação ativa dos atores e engenharia reversa.

Modelagem - as informações obtidas durante a elicitação são registradas e organizadas em modelos de requisitos: casos de uso, cenários e léxicos, entidade relacionamento, dentre outros. A construção destes modelos exige aprofundamento no conhecimento sobre o universo de informação, sobre as necessidades dos usuários e também informações técnicas. Isto remete à atividade de análise para descobrir erros e omissões, sendo muitas vezes necessário retornar à elicitação para esclarecer, acrescentar ou corrigir o conhecimento adquirido.

REAd | Porto Alegre - Edição 78 - N 2 - maio/agosto 2014 - p. 425-460 
Uma proposta de relação de requisitos funcionais para um software de apoio ao processo de inteligência

Análise - além da análise de erros e omissões o processo de definição de requisitos possibilita a análise sob diferentes perspectivas tais como, viabilidade, custo, tempo, prioridades, reuso, completude, corretude, variabilidade, evolução, dentre outras.

\section{REQUISITOS PARA UM SOFTWARE DE INTELIGÊNCIA}

A descrição das atividades existentes em cada uma das etapas dos tipos de inteligência estudados permitiu a geração de uma relação de requisitos funcionais capaz de apoiar a realização de inteligência com foco em ambiente externo à organização.

Sobre a Construção do Processo de Inteligência, por exemplo, Gomes (2008), afirma que a definição de missão e os objetivos é fator de sucesso para o processo de Inteligência Competitiva, pois irão dirigir a construção do mesmo. Gomes (2008) disserta também sobre a importância de mecanismos de distribuição dos produtos de Inteligência Competitiva quando se refere a Disseminação de Relatório de Inteligência.

Por sua vez, quando fala sobre Análise e Produção de Inteligência, Lesca (2003) diz que a seleção de informações é a etapa que consiste em armazenar, dentre as informações coletadas, somente aquelas potencialmente interessantes aos usuários de determinada organização. Esta operação é uma das fases cruciais do processo IEA, pois a ausência de seleção conduz ao excesso de informação e ao inchamento do processo.

Além da descrição das atividades baseada em literatura, as entrevistas com especialistas e profissionais de inteligência enriqueceu a geração da relação de requisitos funcionais, como exemplifica o seguinte quadro.

Quadro 5 - Trechos das entrevistas com profissionais de inteligência

\begin{tabular}{|l|l|}
\hline \multicolumn{2}{|l|}{ Planejamento da Demanda de Inteligência } \\
\hline $\begin{array}{l}\text { Samuel } \\
\text { Molina }\end{array}$ & $\begin{array}{l}\text { "Identificar os KIT's, os key intelligence topic, então esse seria o primeiro passo para } \\
\text { diagnosticar as necessidades de informação da empresa a partir dos seus tomadores de } \\
\text { decisões". }\end{array}$ \\
\hline $\begin{array}{l}\text { Rodrigo } \\
\text { Mazuchowski }\end{array}$ & $\begin{array}{l}\text { "Solicitação de adhoc, aí você fala: eu tenho que saber disso. Aí eu acho que tem que ter um } \\
\text { quando se precisa? Daí sim você concentra todo o seu processo da melhor forma possível } \\
\text { para conseguir atingir e superar a expectativa do cliente". }\end{array}$ \\
\hline Coleta de Informações para Produção de Inteligência
\end{tabular}

Fonte: do autor

REAd | Porto Alegre - Edição 78 - N 2 - maio/agosto 2014 - p. 425-460 
Para este estudo, realizado na Área de Administração, o levantamento de requisitos se restringirá à atividade de elicitação, a descoberta dos requisitos do sistema a ser desenvolvido, incluindo as informações do universo de informação que restringem este sistema.

A partir da consolidação de inteligência e do entendimento do conceito de requisito funcional de software, foi criado um Protocolo Preliminar com a relação de requisitos para um software de apoio ao processo de inteligência. Este protocolo foi validado em uma primeira rodada com Especialistas de Inteligência, que permitiu gerar o Protocolo Intermediário de Requisitos para um Software de Inteligência, o qual por sua vez inspirou o roteiro para as entrevistas em profundidade com Profissionais de Inteligência, resultando no Protocolo de

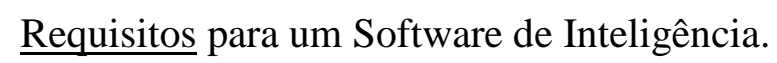

Abaixo, o quadro resultante contemplando as etapas de inteligência e suas respectivas atividades, segundo esquema consolidado, que geraram o Protocolo de requisitos funcionais para um software de inteligência.

Quadro 6 - Protocolo de Requisitos para um Software de Inteligência

\begin{tabular}{|c|c|}
\hline $\begin{array}{l}\text { Etapas } \\
\text { Agrupadas } \\
\text { (Autor) }\end{array}$ & $\begin{array}{l}\text { Protocolo Proposto } \\
\text { (Requisitos funcionais revistos para atendimento } \\
\text { das etapas do processo de inteligência consolidado) }\end{array}$ \\
\hline \multicolumn{2}{|c|}{ Construção do Processo de Inteligência } \\
\hline $\begin{array}{l}\text { Sobre a } \\
\text { Construção } \\
\text { do Processo } \\
\text { de } \\
\text { Inteligência }\end{array}$ & $\begin{array}{l}\text { - Funcionalidade em ambiente de portal para apoio na comunicação e sensibilização de } \\
\text { - } \quad \text { Funcioboradores da empresa; } \\
\text { - Funcionalidade de e-learning para apoio na capacitação da equipe de inteligência; } \\
\text { - Funcionalidade para identificação e registro de problemas de negócios da empresa; } \\
\text { - } \quad \text { Funcionalidade para cadastramento de clientes de inteligência. }\end{array}$ \\
\hline
\end{tabular}

\section{Operacionalização do Processo de Inteligência}

\begin{tabular}{|c|c|}
\hline $\begin{array}{l}\text { Planejamento } \\
\text { da Demanda } \\
\text { de } \\
\text { Inteligência }\end{array}$ & $\begin{array}{l}\text { - Funcionalidade em ambiente de portal para formação das demandas de inteligência. } \\
\text { - } \quad \text { Funcionalidade para cadastramento de demandas de inteligência. } \\
\text { - } \quad \text { Funcionalidade para cadastramento de fontes de informação. } \\
\text { - } \quad \text { Funcionalidade de portal para estimular a realização do processo de inteligência; } \\
\text { - Funcionalidade de fórum de discussão no portal para discussão sobre demandas de } \\
\text { inteligência (REQUISITO NÃO PRIORITÁRIO). } \\
\text { - Funcionalidade de formulário em ambiente de portal para cadastramento dos dados dos } \\
\text { usuários envolvidos no projeto de inteligência; } \\
\text { - Funcionalidade de formulário em ambiente de portal para cadastramento de variáveis } \\
\text { relacionadas às demandas de inteligência e atividades relacionadas à operacionalização do } \\
\text { processo. }\end{array}$ \\
\hline $\begin{array}{l}\text { Coleta de } \\
\text { Informações } \\
\text { para } \\
\text { Produção de } \\
\text { Inteligência }\end{array}$ & $\begin{array}{l}\text { - Busca interna de múltiplos repositórios de informações, como bancos de dados, } \\
\text { documentos do Microsoft Office, relatórios da organização, objetos visuais (mapas, } \\
\text { gráficos e desenhos), e-mail e debates da Intranet; } \\
\text { - } \quad \text { Busca externa de fontes web, como docs HTML e XML, bancos de dados; } \\
\text { - } \quad \text { Monitoramento de alterações em websites; } \\
\text { - Varredura da web usando aplicações baseadas no conceito spider (tecnologia de busca); }\end{array}$ \\
\hline
\end{tabular}


Uma proposta de relação de requisitos funcionais para um software de apoio ao processo de inteligência

\begin{tabular}{|c|c|}
\hline & $\begin{array}{l}\text { - Filtro automático de busca de informações baseado em critérios conforme demandas; } \\
\text { - } \quad \text { Priorização por relevância e validação de documentos recuperados; } \\
\text { - } \quad \text { Sumarização dinâmica de artigos e documentos; } \\
\text { - } \quad \text { Categorização automática das informações coletadas baseado em critérios definidos pelo } \\
\text { - } \quad \text { Funcuário; } \\
\text { - Funcionalidade para gestão de diversos formatos de informações secundárias; } \\
\text { - Funcionalidade de formulário web com ficha de captação para registro das informações; } \\
\text { - } \quad \text { Funcionalidade para checklist de atividades de coleta que o profissional deve executar; } \\
\text { - } \quad \text { Funcionalidade para disparar uma informação a pessoas que podem ajudar o processo. }\end{array}$ \\
\hline $\begin{array}{l}\text { Análise e } \\
\text { Produção de } \\
\text { Inteligência }\end{array}$ & $\begin{array}{l}\text { - Funcionalidade que apoie os analistas na visão das relações entre as informações; } \\
\text { - } \quad \text { Funcionalidade de workflow que permita o envio de informações críticas para especialistas } \\
\text { (da organização ou de fora dela) para análise; } \\
\text { - } \quad \text { Funcionalidade para categorização manual das informações coletadas; } \\
\text { - } \quad \text { Funcionalidade de portal para a organização das informações coletadas; } \\
\text { - } \quad \text { hipcionaleses e geração de lista de ações com responsáveis; } \\
\text { - } \quad \text { Fúltiplas formas de visualização das informações, como os modelos de SWOT (matriz de } \\
\text { - } \quad \text { Disponibilização das informações em ordem cronológica; } \\
\text { - } \quad \text { Tdentificação de relacionamento entre entidades (pessoas, lugares, datas, eventos, etc.); } \\
\text { - } \quad \text { Possibilidade de relacionar análises com dados quantitativos. }\end{array}$ \\
\hline $\begin{array}{l}\text { Disseminação } \\
\text { de Relatório } \\
\text { de } \\
\text { Inteligência }\end{array}$ & $\begin{array}{l}\text { - Funcionalidade para o envio de e-mails e newsletters com os relatórios finais de } \\
\text { inteligência; } \\
\text { - } \quad \text { Funcionalidade de portal para a disponibilização dos relatórios finais de inteligência; } \\
\text { - Máscaras de relatórios padronizados e customizáveis; } \\
\text { - Possibilidade de relacionar e exportar relatórios para formatos do Microsoft Office, } \\
\text { CorelDraw, PDF, formatos multimídia, outras bases de dados e/ou outros } \\
\text { - Capacidade de entregar relatórios em múltiplos formatos, como Intranet corporativa, e-mail } \\
\text { e aparelhos sem fio; } \\
\text { - Funcionalidade que permita agendar as entregas dos produtos e relatórios de inteligência. }\end{array}$ \\
\hline $\begin{array}{l}\text { Avaliação de } \\
\text { Relatório de } \\
\text { Processo de } \\
\text { Inteligência }\end{array}$ & $\begin{array}{l}\text { - Funcionalidade para envio de pesquisa de reação ao usuário para avaliação dos produtos e } \\
\text { do processo de inteligência; } \\
\text { - Funcionalidade de fórum de discussão no portal para debate da dinâmica do processo } \\
\text { (REQUISITO NÃO PRIORITÁRIO). }\end{array}$ \\
\hline
\end{tabular}
Fonte: do autor

\section{CONSIDERAÇÕES FINAIS}

Propor uma relação de requisitos funcionais para um software de inteligência com enfoque nas necessidades das áreas de inteligência brasileiras, entender os diferentes conceitos de inteligência existentes, suas etapas, atividades e semelhanças e estabelecer um esquema de inteligência que consolide as principais atividades de metodologias com foco em ambiente externo estavam postos como os objetivos esperados deste trabalho.

Os diferentes conceitos de inteligência, suas etapas, atividades e semelhanças foram apresentados, permitindo um maior entendimento sobre o conceito de inteligência na literatura acadêmica brasileira (vide Quadro 3) durante mais de dez anos em livros e artigos científicos publicados em congressos de administração de empresas. Foi consolidado um 
Fábio Luiz de Carvalho Rios \& Raquel Janissek-Muniz

esquema de inteligência que agrupou as principais atividades de metodologias com foco em ambiente externo (vide Quadro 4).

Através da realização de entrevistas com especialistas e profissionais em inteligência para identificar os principais aspectos a serem observados em um software que apoiaria um processo de inteligência, bem como a partir da análise das opiniões emitidas nas entrevistas por estes especialistas e profissionais à luz dos requisitos de software para inteligência, uma proposta de relação de requisitos funcionais para um software de inteligência foi realizada e apresentada, conforme Quadro 5.

Os aspectos acima já permitem concluir que os objetivos propostos para este estudo foram amplamente atingidos. Contudo, para ir além, gostaríamos de evocar outras considerações importantes puderam ser extraídas deste estudo.

Uma constatação interessante surgiu a partir de alguns depoimentos das entrevistas com os profissionais de inteligência que apontaram que um software não seria necessário para a construção ou para a operacionalização de um processo de inteligência. Esta não necessidade de software para apoio ao processo de inteligência pode ser ilustrada por alguns trechos das entrevistas, tais como:

Profissional 3, questionado sobre tecnologia de uma forma geral, opinou que "Tecnologia pode ajudar, mas não que seja essencial".

- Profissional 5, questionado sobre Coleta de Informações para Produção de Inteligência, opinou que "Eu valorizo muito as coletas primárias, se tu fazes inteligência através da internet, tu não fazes inteligência".

- $\quad$ Profissional 3, questionado sobre Análise e Produção de Inteligência, "O $e$ Monitora, por exemplo, ele acelera demais esse processo. Mas se eu fosse falar para você hoje, eu tenho dúvidas que ele seria essencial".

- Profissional 1, questionado sobre Disseminação de Relatório de Inteligência, "Se o teu negócio demandou um lugar para disponibilizar os produtos e esse lugar é internet, acho que tem que investir nisso, mas também não acho que é prioridade".

Destes pequenos trechos acima destacados, podemos sugerir que um software de inteligência não é mandatório para a execução do processo de inteligência. Entretanto, percebe-se também que os trechos não falam sobre eventuais desvantagens no uso de softwares para a construção ou operacionalização do processo de inteligência, podendo ser interpretados como possíveis facilitadores ou até mesmo aceleradores para a implantação de sua metodologia. Esta percepção poderia recomendar uma sugestão de um estudo futuro 
Uma proposta de relação de requisitos funcionais para um software de apoio ao processo de inteligência

focado em comparar uma operacionalização de processo de inteligência com software e outro sem software de apoio às suas atividades.

Outra consideração interessante é o fato de que um software de inteligência parece poder ser mais útil se contemplar funcionalidades de apoio à operacionalização de tal processo. No que tange a construção do processo de inteligência, o pequeno volume de requisitos identificados parece sinalizar que um software faz menos sentido. Entretanto, é importante destacar que as entrevistas com os especialistas demonstraram que o maior ganho está na construção do processo e na manutenção deste processo. O dia-a-dia deste processo, no sentido de Planejar, Coletar, Analisar, etc., parece ser simples em sua visão. Um software de inteligência apoiaria muito mais nesta questão inicial e de manutenção do que na rotina. Por outro lado, os profissionais de inteligência falam muito mais de funcionalidades para apoiar no dia-a-dia da geração de produtos de inteligência e muito menos em termos de construção e manutenção de processos. Esse fenômeno pode acontecer por dois motivos: ou porque os profissionais ainda não têm maturidade suficiente e experiência em inteligência ou porque a visão dos especialistas está equivocada e o dia-a-dia é realmente mais complexo para os profissionais.

Ainda na mesma linha de raciocínio, foi possível perceber uma falta de requisitos propostos ou meramente tangenciados pelos profissionais em etapa de Construção de Processo de Inteligência e Planejamento da Demanda de Inteligência. Isto pode sinalizar uma falta de visão destes profissionais sobre o que um software de inteligência pode contribuir. Nem mesmo tendo provocado os entrevistados com perguntas que pudessem ajudá-los a perceber a possibilidade de um software atender nestas questões, ainda assim não houve respostas consistentes. Conforme lembrou o Profissional 1 na primeira entrevista, parafraseando o ex-presidente da Sony, Akio Morita: “Os clientes não têm ideia dos que eles querem". Poderíamos completar ainda com uma célebre frase do empresário americano Henry Ford: "Se eu tivesse perguntado às pessoas o que queriam, elas provavelmente teriam me dito cavalos mais rápidos".

Esta provocação acima também poderia recomendar uma sugestão de estudo futuro voltado, de certa forma, para a inovação na construção de softwares. Os melhores softwares são aqueles nos quais a maior parte dos insumos veio de pesquisas junto a usuários finais ou são aqueles que foram concebidos por quem conhece profundamente o negócio que o software vai automatizar e possui conhecimentos em relação à construção de softwares? 
Fábio Luiz de Carvalho Rios \& Raquel Janissek-Muniz

Este estudo também pode nos fazer perceber que cada um dos requisitos funcionais de software identificados e propostos no resultado deste trabalho poderia ser profundamente explorado, dando origem a diversas novas propostas de pesquisa em inteligência.

\section{REFERÊNCIAS}

AZEVEDO JR, D.; CAMPOS, R. Definição de Requisitos de Software Baseada Numa Arquitetura de Modelagem de Negócios. Produção, São Paulo, v. 18, n.1, p. 026-048, jan-abr 2008.

BARBALHO, C. R. S. Construindo competências: formação de recursos humanos para inteligência competitiva. In: Congresso Ibero Americano de Gestão do Conhecimento e Inteligência Competitiva (GeCIC), 2006, Curitiba. Anais... 2006.

BARDIN, L. L'analyse de contenu. Paris: PUF, 8. Ed.,1996.

BRITO, P. F., TEIXEIRA, D., e NOLETO, D. A. O Padrão RDF como facilitador no processo de Inteligência Competitiva. In: Congresso Anual de Tecnologia da Informação (CATI), 2004, São Paulo. Anais..., 2004.

CARDOSO JR., W. F. Inteligência Empresarial Estratégica: Método de implantação de inteligência competitiva em organizações. Tubarão: Ed. Unisul, 2005.

CARDOSO JR, W. F. e CARDOSO, A. C. F. A Função Inteligência Competitiva Aplicada em Instituições de Ensino Superior: O Caso da Universidade do Sul de Santa Catarina. In: Congresso Ibero Americano de Gestão do Conhecimento e Inteligência Competitiva (GeCIC), 2006, Curitiba. Anais... 2006.

CARON-FASAN, M-L. e JANISSEK-MUNIZ, R. Análise de informações de inteligência estratégica antecipativa coletiva: proposição de um método, caso aplicado e experiências. RAUSP, v.39, n.3, 2004. p. 205-219.

CARVALHO, A. M. A., SANTOS, E.M., CAMPOS, L.M., CUNHA, R.A.A. e BORGES, M.E.N. Preparando o terreno para a inteligência competitiva: proposta de metodologia para capacitação da equipe de inteligência competitiva. In: Congresso Ibero Americano de Gestão do Conhecimento e Inteligência Competitiva (GeCIC), 2006, Curitiba. Anais... 2006.

CAVALCANTI, E. P. e CAVALCANTI, E. R. Gap de Inteligência na Perspectiva dos Negócios. In: 29² EnANPAD, 2005, Brasília. Anais... 2005. 
Uma proposta de relação de requisitos funcionais para um software de apoio ao processo de inteligência

CAVALCANTI, E. P. Inteligência Empresarial e o sucesso nos negócios. In: $28^{\circ}$ EnANPAD, 2004, Curitiba. Anais..., 2004.

DAVENPORT, T. H. Ecologia da informação: por que só a tecnologia não basta para o sucesso na era da informação. Tradução: Bernadete Siqueira Abrão. São Paulo: Futura, 1998.

DEGENT, R. J. A importância estratégica e o funcionamento do serviço de inteligência empresarial. RAE, v.26, n.1, 1986. p. 77-83.

FERNANDES DA SILVA, L. Uma Estratégia Orientada a Aspectos para Modelagem de Requisitos. Rio de Janeiro: PUC-Rio, 2006. Tese (Doutorado em Informática). Rio de Janeiro, 2006.

FREITAS, H. e JANISSEK, R. Análise Léxica e Análise de Conteúdo: técnicas complementares, seqüências e recorrentes para análise de dados qualitativos. Porto Alegre. Sphinx-Sagra (distrib.). 2000, 176 p.

FREITAS, H. e JANISSEK-MUNIZ, R. Uma proposta de plataforma para Inteligência Estratégica. In: Congresso Ibero Americano de Gestão do Conhecimento e Inteligência Competitiva (GeCIC), 2006, Curitiba. Anais... 2006.

FREITAS, P. H., FREITAS, H. , JANISSEK-MUNIZ, R., e GERSON, G. Praticando o Conceito de Inteligência Estratégica Antecipativa (IEA) em uma Empresa de Software Médico. In: Congresso Ibero Americano de Gestão do Conhecimento e Inteligência Competitiva (GeCIC), 2006, Curitiba. Anais... 2006.

FREITAS, P., FREITAS, H., e GENSAS, G. A Inteligência Estratégica no apoio à Decisão de uma Empresa de TI. REAd. Porto Alegre. Vol. 13 No. 2, Mai - Jun de 2007.

FULD, L. M. The new competitor intelligence: the complete resource for finding, analyzing, and using information about your competitors. New York: Wiley, 1995.

FULD, L. M. Intelligence Software Report. Massachusetts: Fuld Company, 2008.

GASPARINI, L. V. L. Práticas de Inteligência Organizacional (IO) em Organizações Tangaraenses: mapeamento da dimensão de componentes na visão de seus gestores. In: ENCONTRO DE ADMINISTRAÇÃO DA INFORMAÇÃO (ENADI), 2007, Florianópolis. Anais ... Rio de Janeiro: ANPAD, 2007.

GOMES, E. Apostila da disciplina de inteligência competitiva do curso MBA em gestão de negócios e inteligência competitiva. Rio de Janeiro: SENAC, 2008.

REAd | Porto Alegre - Edição 78 - Nº 2 - maio/agosto 2014 - p. 425-460 
Fábio Luiz de Carvalho Rios \& Raquel Janissek-Muniz

GOMES, E. Inteligência competitiva como ferramenta de auxílio à estratégia das organizações: proposta de um processo. Rio de Janeiro: UFRJ, 2005. Tese (Doutorado em Ciências em Engenharia de Produção) - Programa de Pós-Graduação em Engenharia de Produção da Universidade Federal do Rio de Janeiro. Rio de Janeiro, 2005.

GOMES, E. e BRAGA, F. Inteligência Competitiva: Como Transformar Informação em um Negócio Lucrativo. Rio de Janeiro: Campus, 2004.

GONÇALVES, C. A. e MACIEL, C. A. F. O papel das estratégias tácitas na competitividade organizacional: uma contribuição teórica à inteligência estratégica organizacional. In: $25^{\circ}$ EnAnpad, 2001, Campinas. Anais..., 2001.

HOFFMANN, W. A. M. e CHEMALLE, K. E. Gestão da informação para integrar inteligência competitiva em micro e pequena empresas de arranjos produtivos locais. In: Congresso Ibero Americano de Gestão do Conhecimento e Inteligência Competitiva (GeCIC), 2006, Curitiba. Anais... 2006.

INFOMONEY. Disponível em http://www.infomoney.com.br/noticias/noticia/1795106., 2010.

JANISSEK-MUNIZ, R. Veille Anticipative Stratégique en PMI: Vers un nouvel usage du site Web pour provoquer des informations «terrain» afin d'amorcer des innovations: Concept, instrumentation et validation. Thèse en Doctorat Sciences de Gestion. Grenoble 2 UPMF CERAG, 2004.

JANISSEK-MUNIZ, R., FREITAS, H., LESCA, H., e CARON-FASAN, ML. Inteligência Estratégica Antecipativa e Coletiva (IEAc): transferência e adaptação de conhecimentos metodológicos visando propor soluções e promover a IEAc no Brasil. In: $29^{\circ}$ EnANPAD, 2005, Brasília. Anais..., 2005.

JANISSEK-MUNIZ, R., LESCA, H., e FREITAS, H. Desenvolvimento da Capacidade de Antecipação pela Identificação d Captação de Indícios Antecipativos Em Contexto De Inteligência Estratégica Antecipativa. Colóquio IFBAE. Anais... 2007. Porto Alegre.

JANISSEK-MUNIZ, R., LESCA, H., e FREITAS, H. Inteligencia Estratégica: Desarrollo De la Capacidad de Antelación por la Identificación de Indicios Anticipativos. Revista Economia e Gestão, 2008.

KAHANER, L. Competitive Intelligence: how to gather, analyze, and use information to move your business to the top. New York: Touchstone, 1996. 
Uma proposta de relação de requisitos funcionais para um software de apoio ao processo de inteligência

KRAFTA, L. Gestão da Informação como base da ação comercial de uma pequena Empresa de TI. Dissertação de Mestrado em Administração. Universidade Federal do Rio Grande do Sul. Porto Alegre. Rs. 2007.

PEREIRA, L. DEBIASI, F., e ABREU, A. F. Inovação tecnológica e inteligência competitiva: um processo interativo. REAd, ed. 21, v.7, n.1, 2001.

LESCA, H. Veille stratégique: La méthode L.E.SCAnning ${ }^{\circledR}$, Editions EMS. 180 p., 2003.

LESCA, H.; JANISSEK-MUNIZ, R. e FREITAS, H. Inteligência Estratégica Antecipativa: uma ação empresarial coletiva e pró-ativa, 2003.

LINS, A. e QUANDT, C. O. Criando Inteligência Competitiva Através da Utilização da Ferramenta de Data Mining: Estudo no Setor de Telecomunicações. In: $1^{\circ}$ Encontro de Administração da Informação (EnADI), 2007, Florianópolis. Anais..., 2007.

LOPES, L. T.; MAJDENBAUM, A.; AUDY, J. L. N. Uma proposta para processo de requisitos em ambientes de desenvolvimento distribuido de software. In: WORKSHOP EM ENGENHARIA DE REQUISITOS (WER'03 - SBC), 2003, Piracicaba. Anais ...Rio de Janeiro: PUCRJ, 2003. v. 1. p. 78-92.

MACHADO, C. R., ROTHER, R. G., TRZECIAK, D. S., DE ABREU, A. F., DE ABREU, P. F., e FIALHO, F. A. P. O papel da memória de trabalho no suporte a sistemas de inteligência competitiva. In: Congresso Ibero Americano de Gestão do Conhecimento e Inteligência Competitiva (GeCIC), 2006, Curitiba. Anais... 2006.

MALHOTRA, N. K. Pesquisa de Marketing: uma orientação aplicada. 3. ed. Porto Alegre: Bookman, 2001.

MARCHAND, D. A., KETTINGER, W. J., e ROLLINS, J. D. Desempenho empresarial e gestão da informação: a visão do topo. In: DAVENPORT, T. H., MARCHAND, D. A., e DICKSON, T. Dominando a Gestão da Informação. Trad.: Carlo Gabriel Porto Bellini e Carlos Alberto Silveira Netto Soares. Porto Alegre: Bookman, 2004.

MARCIAL, E. C. e COSTA, A. J. L. Uso de Cenários prospectivos na estratégia empresarial: evidência especulativa ou Inteligência Competitiva. In: $25^{\circ}$ EnANPAD, 2001, Campinas. Anais..., 2001.

MARCIAL, E. C. e ORNELAS, A. C. A Interdisciplinaridade da Atividade de Inteligência Competitiva: Analise do Curriculo Lattes. In: $31^{\circ}$ EnANPAD, 2007, Rio de Janeiro. Anais..., 2007. 
Fábio Luiz de Carvalho Rios \& Raquel Janissek-Muniz

MILLER, J. P. O milênio da inteligência competitiva. Porto Alegre: Bookman, 2002.

MOORI, R. G., KIMURA, H., e KAYO, E. K. Informações da Inteligência Competitiva e Aplicações no Telescopic Observations e do Analytic Hierarchy Process. In: Congresso Ibero Americano de Gestão do Conhecimento e Inteligência Competitiva (GeCIC), 2006, Curitiba. Anais... 2006.

MORESI, E. A. D. Perspectivas de pesquisa em inteligência organizacional. In: Congresso Ibero Americano de Gestão do Conhecimento e Inteligência Competitiva (GeCIC), 2006, Curitiba. Anais... 2006.

MORESI, E. A. D., ALCANTARA, A., e PRADO, H. A. Cenários prospectivos, monitoração ambiental e metadados. In: Congresso Anual de Tecnologia da Informação (CATI), 2005, São Paulo. Anais.... São Paulo: FGV-EAESP, 2005.

OLIVEIRA, M. M. Como Fazer Pesquisa Qualitativa. São Paulo: Vozes, 2007.

OLIVEIRA, R. D., PINTO, A. O., e SALLES, J. A. A. A aplicabilidade da inteligencia competitiva: um estudo de caso nas pequenas e médias empresas em ambiente de aglomeração industrial. In: Congresso Ibero Americano de Gestão do Conhecimento e Inteligência Competitiva (GeCIC), 2006, Curitiba. Anais... 2006.

PASSOS, A. Inteligência Competitiva: como fazer IC acontecer na sua empresa. São Paulo: LCTE, 2005.

PAULA FILHO, W. P. Engenharia de software: fundamentos, métodos e padrões. Rio de Janeiro: Livros Técnicos e Científicos, 2001.

PEREIRA, L. K.; DEBIASI, F.; ABREU, A. F. de. Inovação tecnológica e inteligência competitiva: um processo interativo. READ Revista Eletrônica de Administração, Edição 21, v.7, n.3, jul. 2001.

PETRINI, M., FREITAS, M. T., e POZZEBON, M. Inteligência de Negócios ou Inteligência Competitiva? Noivo Neurótico, Noiva Nervosa. In: $30^{\circ}$ EnANPAD, 2006, Salvador. Anais..., 2006.

PETRINI, M., POZZEBON, M., e FREITAS, M. T. Qual é o Papel da Inteligência de Negócios (BI) nos Países em Desenvolvimento? Um Panorama das Empresas Brasileiras. In: EnANPAD, 2004, Curitiba. Anais... 2004. 
Uma proposta de relação de requisitos funcionais para um software de apoio ao processo de inteligência

PETRINI, M., POZZEBON, M., e MEIRELLES, F. Incorporando Gestão da Sustentabilidade aos Sistemas de Inteligência de Negócios. In: $31^{\circ}$ EnANPAD, 2007, Rio de Janeiro. Anais..., 2007.

POZZEBON, M.; SOARES, R. O.; DORNELAS, J. S. Análises sobre a desregulamentação da telefonia no Brasil. Revista Eletrônica de Administração, Porto Alegre, v. 3, n. 1, p. 1-29, mai.-jun. 1997.

QUANDT, C. O. e FERNANDES, A. C. C. B. Aplicação do Conceito de Inteligência Competitiva e seu Impacto no Processo Estratégico em Organizações do Terceiro Setor. In: $27^{\circ}$ EnANPAD, 2003, Atibaia - SP. Anais..., 2003.

RAUTER, A. e VANTI, A. A. Configuração informacional para a gestão administrativa do negócio educacional com a análise da tecnologia da informação Business Intelligence (BI) um estudo de caso. In: Congresso Anual de Tecnologia da Informação (CATI), 2005, São Paulo. Anais.... São Paulo: FGV-EAESP, 2005.

REGINATO, L. e NASCIMENTO, A. M. As Ferramentas Business Intelligence apoiando o Controle Organizacional. In: Congresso Anual de Tecnologia da Informação (CATI), 2006, São Paulo. Anais.... São Paulo: FGV-EAESP, 2006.

REZENDE, D. A. Alinhamento estratégico da tecnologia da informação ao business plan: contribuição para a inteligência empresarial das organizações. READ, Porto Alegre, edição 31, v. 9, n. 1, 2003.

RIOS, F. L. C.; Uma proposta de requisitos para um software de apoio ao processo de inteligência. Dissertação (mestrado) - Universidade Federal do Rio Grande do Sul. Escola de Administração. Programa de Pós-Graduação em Administração, Porto Alegre, BRRS, 2010. 240 p.

RIOS, F. L. C.; STRAUSS, L.; BRODBECK, A. e JANISSEK-MUNIZ, R. Inteligência Competitiva, Empresarial, Estratégica ou de Negócios? Um Olhar a partir da Administração de Empresas. In: IFBAE, 2011, Franca SP. Anais do 6 IFBAE, 2011.

RODRIGUES, J. R. G.; NUNES, P. M. O uso do balanced scorecard como núcleo de business intelligence: um poderoso habilitador da excelência das decisões sobre temas qualitativos e estratégicos da organização moderna. In: ENCONTRO DA ASSOCIAÇÃO NACIONAL DE PÓS-GRADUAÇÃO E PESQUISA EM ADMINISTRAÇÃO (ENANPAD), 25, 2001, Campinas. Anais ... Rio de Janeiro: ANPAD, 2001.

RODRIGUES, L. C.; TOLEDO, L.A. Alinhamento entre sistema de inteligência competitiva e gerenciamento da tecnologia de informação. In: ENCONTRO DA ASSOCIAÇÃO 
NACIONAL DE PÓS-GRADUAÇÃO E PESQUISA EM ADMINISTRAÇÃO

(ENANPAD), 30, 2006, Salvador. Anais ... Rio de Janeiro: ANPAD, 2006.

RODRIGUEZ Y RODRIGUEZ, M. V.; FONTANA, E. W. Inteligência competitiva: nível de uso e influência nas receitas nos pequenos negócios exportadores. READ, Porto Alegre, edição 45, v. 11, n. 3, 2005.

ROESCH, S. M. A. Projetos de Estágio e de Pesquisa em Administração: guia para estágios, trabalhos de conclusão, dissertações e estudos de caso. $3^{\text {a }}$ ed. São Paulo: Atlas, 2005.

RUTHES, S.; NASCIMENTO, D. E.; DERGINT, D. Inteligência competitiva: a propriedade industrial como subsídio para a formulação de estratégias focadas no desempenho local. In: CONGRESSO IBERO AMERICANO DE GESTÃO DO CONHECIMENTO E INTELIGÊNCIA COMPETITIVA (GECIC), 2006, Curitiba. Anais ...Brasília: IBICT 2006. 1 CD-ROM.

SANTIAGO JR, W. M.; COSTA DE MENDONÇA, J.R. Gestão de performance baseada em business intelligence e interfaces de monitoria: o caso de uma transportadora. In:

ENCONTRO DE ADMINISTRAÇÃO DA INFORMAÇÃO (ENADI), 2007, Florianópolis. Anais ... Rio de Janeiro: ANPAD, 2007.

SAPIRO, A. Inteligência empresarial: a revolução informacional da ação competitiva. RAE, São Paulo, v.33, n. 3, p. 106-124, 1993.

SGUARIO DOS REIS, E.; ANGELONI, M. T. Business intelligence como tecnologia de suporte à definição de estratégias para a melhoria da qualidade do ensino. In: ENCONTRO DA ASSOCIAÇÃO NACIONAL DE PÓS-GRADUAÇÃO E PESQUISA EM ADMINISTRAÇÃO (ENANPAD), 30, 2006, Salvador. Anais ... Rio de Janeiro: ANPAD, 2006.

SILVA, E.L.; MENEZES, E.M.; Metodologia da pesquisa e elaboração de dissertações. Florianópolis, Laboratório de Ensino a Distância da Universidade Federal de Santa Catarina, Brasil. 2001.

SPINOLA, A. T. P.; GARCIA, L. G.; HOFFMANN, W. A. M.; GREGOLIN, J. Â. R. Desenvolvimento de uma metodologia utilizando o QFD como ferramenta analítica da inteligência competitiva aplicada a empresa de pequeno porte do pólo de jóias folheadas de Limeira. In: CONGRESSO IBERO AMERICANO DE GESTÃO DO CONHECIMENTO E INTELIGÊNCIA COMPETITIVA (GECIC), 2006, Curitiba. Anais ... Brasília: IBICT 2006. 1 CD-ROM.

SOUZA, M. Inteligência competitiva: os setores portadores de futuro para o Paraná. In: CONGRESSO IBERO AMERICANO DE GESTÃO DO CONHECIMENTO E

REAd | Porto Alegre - Edição 78 - Nº 2 - maio/agosto 2014 - p. 425-460 
Uma proposta de relação de requisitos funcionais para um software de apoio ao processo de inteligência

INTELIGÊNCIA COMPETITIVA (GECIC), 2006, Curitiba. Anais ... Brasília: IBICT 2006. 1 CD-ROM.

TARAPANOFF, K. Inteligência Organizacional e Competitiva. Brasília: Editora UNB, 2001.

TARAPANOFF, K. Inteligência, informação e conhecimento. Brasília: IBICT, 2006.

TURINE, M.A.S.; MASIERO, P.C. Especificação de requisitos: uma introdução. Instituto de Ciências Matemáticas de São Carlos, USP. 1996.

VALENTIM, M. L. P. Inteligência competitiva organizacional: ferramenta ou processo? In: CONGRESSO IBERO AMERICANO DE GESTÃO DO CONHECIMENTO E INTELIGÊNCIA COMPETITIVA (GECIC), 2006, Curitiba. Anais ... Brasília: IBICT 2006. 1 CD-ROM.

VARGAS, L. M.; SOUZA, R. F. O ator de inteligência competitiva (IC) nas empresas: habilidades profissionais e exigências do mercado. READ, Porto Alegre, edição. 24, v. 7, n. 6, 2001.

VERGARA, S. C. Projetos e Relatórios de Pesquisa em Administração. São Paulo: Atlas, 2006.

VIEIRA, D. V.; OLIVEIRA, F. C. Inteligência competitiva e monitoramento ambiental em empresas exportadoras. In: CONGRESSO ANUAL DE TECNOLOGIA DA INFORMAÇÃO (CATI), 2006, São Paulo. Anais ... São Paulo: FGV-EAESP, 2006. 1 CD-ROM.

VIEIRA, M. M. F. e ZOUAIN, D. M. Pesquisa Qualitativa em Administração. São Paulo: FGV Editora, 2007.

ZANLORENCI, E. P.; BURNETT, R. C. Modelo para qualificação da fonte de informação cliente e de requisito funcional. In: WORKSHOP EM ENGENHARIA DE REQUISITOS, 1, 1998, Maringá. Anais ...Rio de Janeiro: PUCRJ, 1998, p 39-48. 